Research Article

\title{
Simulation Parameter Test and Seepage Effect Analysis of Pile-Anchor Support for Binary Slope
}

\author{
Xuhe Gao $\mathbb{D}^{1},{ }^{1}$ Weiping Tian, ${ }^{1}$ Zhipei Zhang, ${ }^{2}$ Jiachun Li, ${ }^{1}$ and Hongliang $\mathbf{Q i}^{1}$ \\ ${ }^{1}$ Key Laboratory of Highway Engineering in Special Region, Ministry of Education, Chang'an University, Xi'an, \\ Shaanxi 710064, China \\ ${ }^{2}$ College of Geology and Environment, Xi'an University of Science and Technology, Xi'an, Shaanxi 710054, China
}

Correspondence should be addressed to Xuhe Gao; 81706037@qq.com

Received 4 June 2020; Revised 25 August 2020; Accepted 5 September 2020; Published 29 September 2020

Academic Editor: Rafael J. Bergillos

Copyright (C) 2020 Xuhe Gao et al. This is an open access article distributed under the Creative Commons Attribution License, which permits unrestricted use, distribution, and reproduction in any medium, provided the original work is properly cited.

It is a difficult point in the field of geotechnical engineering to test the simulation parameters of the pile-anchor supporting structure of slope excavation and analyze the effect of seepage on the stress of the structure. This study relies on the right side slope treatment project of a highway in Guizhou Province. Aiming at the defect that the current numerical simulation parameter selection is fuzzy, the deep displacement monitoring data and $P$ value inspection method are used to check the simulation parameters. We establish a 2D finite element model of slope excavation and support. The superposition calculation method of pore water pressure was used to analyze the stress characteristics of the slope-supporting structure after applying steady-state seepage. The analysis shows the following. (1) Initial support stage: the steady-state seepage causes the axial force extreme value of the prestressed anchor cable to increase by $11.22 \%$ at this stage. (2) Secondary support stage: the steady-state seepage reduces the shear limit of the antislide pile by $3.11 \%$ and the bending moment by $14.90 \%$. (3) Comparative analysis of the two supporting phases: the newly constructed pile-anchor supporting structure has a significant effect on the original pile-anchor supporting structure. At the same time, the bending and shearing resistance of the newly added antislide piles has not been fully exerted. The research results provide new ideas for the research on the safety control ability of the slope support construction process.

\section{Introduction}

Slopes can be classified into three major categories-soil slopes, rock slopes, and rock-soil mixed slopes-based on their composite materials. In rock-soil mixed slopes, the lower part of the slope is a rock layer, whereas the upper part is a soil layer; these slopes are also known as binary-structure slopes. As there are many mountains in southwestern China, buildings and infrastructure are frequently built in the mountains. The binary-structure slope is a common structural form in this setting as the mountain surface is overlaid by a loosely accumulated soil layer and the lower layer is hard bedrock. As the structural plane is the interface between the soil and rock layers, it is important to conduct a qualitative analysis of the factors that affect slope stability and the mechanisms of slope instability and to quantitatively evaluate slope protection methods $[1,2]$.
1.1. Existing Research on Antislide Pile Supporting Structures. The pressure method is currently widely used in a variety of engineering projects and requires consideration of two key factors for effective implementation: the size and distribution of the landslide thrust behind the pile and the calculated resistance of the soil in front of the pile. In China, the transfer coefficient method is the standard method used to calculate landslide thrust. Dai et al. [3] determined that the landslide thrust distribution and its reasonable operating point are likely related to the landslide type, sliding surface shape, and stratum properties. Notably, the slope protection pile is a passive pile, and landslide thrust can only be generated when displacement of the soil around the pile occurs. However, the central concept of the pressure method is directly contrary to the actual pile-soil interactions. Thus, the displacement method may be used to calculate the pilesoil interaction in a manner that is more consistent with the 
actual interactions. In [4], three groups of spring columns were used to describe the relationship between piles and soil. Based on the characteristics of the three groups of spring columns and the displacement of the soil, the strength of the pile body was determined. Compared with the pressure method, the displacement method improves the simulation of the pile-soil interaction, but it is limited due to the need to estimate the free lateral displacement of the rock and soil body surrounding the pile.

Numerical analysis methods must not only consider the pile-soil interaction but also simulate the soil arching effect. These methods can also directly or indirectly determine the most dangerous slope sliding surface and internal pile forces. Therefore, numerical analysis methods have experienced unprecedented development in recent decades. For example, Chen [5] used the structural elements built by FLAC3D software to simulate prestressed anchor cable antislide columns and quantitatively analyzed the stress and deformation characteristics of the piles before and after reinforcement. However, there was no discussion of parameter verification or process analysis methods in this study, which is necessary for improved numerical analysis studies.

\subsection{Existing Research on Prestressed Anchor Supporting} Structures. Hyet et al. [6], Jiao et al. [7], and Wilson et al. [8] used field and laboratory tests to identify that the characteristic of the cement mortar is one of the main factors affecting the bearing capacity of the bolts in prestressed anchor supporting structures. The water-cement ratio (W/ C), anchorage length, and confining pressure will also have an effect on the bolts' anchorage bearing capacity. Guo and Wang [9] studied and analyzed the supporting effects and action capabilities of anchor rods under different geological conditions based on the common theory of bolt load. They concluded that in fractured geological rock layers, the anchor rods significantly affect the overall stability and that this effect varies with the geological engineering conditions. Zhu et al. [10] used the Duncan-Zhang, Hoek-Brown, and Mohr-Coulomb yield criteria to conduct a mechanical analysis of different rock support effects. The study concluded that after the rock is anchored, the $C$ value and shear strength may be increased. However, there was no discussion of the parameters used in the calculation of the strength criterion.

He et al. [11] noted that there is a discrepancy between the simplified assumptions of traditional design methods and the measured results. Considering the effects of a gradual loss of mechanical bite force, chemical adhesive force, and interfacial friction force on the interface bond strength, the study established a new theoretical model and a friction contact interface element. These tools can be used to simulate the mechanical properties of the anchor rod and the rock-soil interface using a numerical model for simulation and analysis. The study also provided a comparative analysis of the traditional design methods and the measured results, which proves that the traditional design process has certain errors. However, similar to previous studies, there was no analysis of the effectiveness or validity of the parameter selection nor was there a discussion of process analysis.

There have been a number of other studies on prestressed anchor supporting structures. Jia et al. [12] compared the flexible support of prestressed anchors with soil nail support under the same geological conditions and showed that prestressing can effectively control the slip field of foundation pits. Wei and Chen [13] discussed the limitations of current numerical simulations in geotechnical engineering and developed a calculation process using both the strength reduction and bolt optimization calculation models that considers the friction effect of the bolt along the grouting body. Lin and Cao [14] analyzed the effect of bolt length on slope stability and the mechanical response to the bolt by establishing a double spring element numerical model. The analysis revealed that there is an effective anchor length when the anchor rod maximally reinforces the slope. Thus, for permanent slope-supporting anchor structures, the length of the bottom anchor should be appropriately increased. Despite the important results of these studies, none discussed the validation of their parameter selection methods or provided a full process analysis, limiting the potential applications of these results.

1.3. Overview of the Present Study. In summary, over the past few decades, many scholars have conducted research on the stability of soil slopes and pile-anchor supporting structures. For example, Ong et al. [15-19] studied the characteristics of pile-soil interaction when using antislide piles to support the slope formation during excavation. At the same time, there are also scholars who conducted research on the seepage mechanism of slope excavation [20-22]. While progress has been made, most studies assume that the slope body is composed of homogeneous soil; however, the actual geological conditions of most slopes are more complex and heterogeneous. Furthermore, most work to date has relied on a single indoor experiment, numerical simulation of a given parameter, or theoretical exploratory qualitative analysis based on mathematical calculations. Based on previous studies, we investigated the right side slope treatment project of a highway in Guizhou Province and used the strength reduction method to analyze the binarystructure slope. Finite element simulation was performed to model the deformation process of the slope and pile-anchor supporting structures in response to superimposed pore water pressure. Finally, we provide a validation of the simulation parameters and an analysis of the process used in this work. The results of this study may therefore provide a basis for the design and construction of slope management projects, while enriching the theory and research methods for analysis of supporting structure stability under the condition of seepage flow on binary slopes.

\section{Materials and Methods}

\subsection{Study Area Characteristics}

2.1.1. Slope Sliding History. During the excavation of the slope, tension cracks formed on the ground surface three 
times. Accordingly, different degrees of slippage occurred, and construction safety was seriously affected. The first instance occurred on April 3, 2014, when ground cracks formed in section $\mathrm{K} 5+680$ to $\mathrm{K} 5+770$, causing slope slip. The second instance occurred on June 1, 2014, in the $\mathrm{K} 5+540$ to $\mathrm{K} 5+680$ section of the right slope between 30 and $50 \mathrm{~m}$ north of the west side. Due to the lack of timely treatment and continuous rainfall, the first landslide continued to develop, inducing a second traction slip. The third occurrence was on September 28, 2014, when ground surface subsidence occurred between $\mathrm{K} 5+385$ and $\mathrm{K} 5+500$.

2.1.2. Regional Meteorology and Hydrology. The climate of the region is characterized by four distinct seasons, including a hot, rainy season and a bright, hot, dry season. The average rainfall is $1369.6 \mathrm{~mm}$ and the precipitation is concentrated between May and October. A rain-source " $V$ "-shaped valley is present in this slope section.

The surface water in the landslide area is mainly rainsource ditch and stream water formed by surface runoff due to atmospheric precipitation. This surface water has a scouring effect on the slope during the rainy season. Based on the lithology and the hydrodynamic characteristics of this slope section, the groundwater in this area is divided into loose accumulation pore water and bedrock fissure water.

2.1.3. Arrangement of Monitoring Points. There are five deep displacement monitoring points arranged in this slope section (Table 1).

The schematic of the deep displacement monitoring point locations is shown in Figure 1, and a cross-sectional view of the slope is shown in Figure 2.

2.2. Strength Reduction Theory. The safety factor of slope stability is defined in the strength reduction method as the degree to which the shear strength of the rock and soil is reduced when the slope just reaches the critical failure state. Thus, the safety factor is the ratio of the actual rock and soil shear strength to the reduced shear strength at failure. The main points of the strength reduction method are defined by equations (1) and (2), which are used to adjust the strength indices of the rock and soil. Based on these formulas, numerical analysis of the slope stability was performed, and the shear strength reduction factor was continuously increased. The calculation was repeated until the slope reached the critical failure state, and the strength reduction factor at this point was taken as the safety factor $F_{\mathrm{s}}$. The formulas are as follows:

$$
\begin{array}{r}
c_{F}=\frac{c}{F_{\text {trial }}}, \\
\tan \left(\varphi_{F}\right)=\frac{\tan \varphi}{F_{\text {trial }}},
\end{array}
$$

where $c$ is the cohesive force, $\varphi$ is the friction angle, $c_{F}$ is the reduced cohesive force, $\varphi_{F}$ is the reduced friction angle, and $F_{\text {trial }}$ is the strength reduction factor.

\subsection{Numerical Model Development}

2.3.1. Simulation Assumptions and Regions. Midas/GTS software was selected for modelling. By analyzing the geological conditions of the slope and the actual conditions of excavation, support, and the environment in which the slope is located, the following assumptions were made to simplify the numerical analysis:

(1) Rock and soil form an ideal elastoplastic body, which obeys the Mohr-Coulomb strength criterion.

(2) The impact of groundwater and seepage on the overall project can be simplified into a stable flow.

(3) Each structural unit in the pile-anchor supporting structure is completely elastic. The supporting pile obeys an elastic constitutive model and the anchor cable behaves as an implanted truss unit.

According to the $\mathrm{K} 5+420$ cross-sectional diagram (Figure 2), combined with the requirements of the simulation calculations, the default model size along the route $(Z$ direction) was $1 \mathrm{~m}$, with a total width of $150 \mathrm{~m}$ and a height of $80 \mathrm{~m}$. Define the geotechnical layer grid unit as the plane strain unit.

Initial Support Construction Stage. Antisliding piles were added at the third-level platform (see Figure 2). The crosssectional width ( $X$ direction) of the antisliding piles was $3 \mathrm{~m}$, and the length ( $Y$ direction) of the piles was $30 \mathrm{~m}$. The antislide pile adopts a $1 \mathrm{D}$ element in which the mesh is first divided and then the free line is extracted from the node so as to obtain a linear beam element for calculation. Three levels of anchor cables were added for grades 2 and 3. The slope was reinforced every $3 \mathrm{~m}$ by prestressed anchor cables with a downward tilt of $20^{\circ}$. The total length of the anchor cable was $20 \mathrm{~m}$, the anchor section was $10 \mathrm{~m}$ long, and the anchor cable prestress was $500 \mathrm{kN}$.

In the model of the second support construction stage, an anchor cable beam was added to the top of the antisliding pile on the third-level platform. The anchor cable had a downward tilt of $28^{\circ}$, a length of $33 \mathrm{~m}$, an anchor section length of $11 \mathrm{~m}$, and a prestress of $750 \mathrm{kN}$. The antisliding pile had a cross section width ( $X$ direction) of $3 \mathrm{~m}$ and a length ( $Y$ direction) of $33 \mathrm{~m}$. The definition method of antislide pile is consistent with the initial construction. The anchor cable at the top of the pile was angled downward by $20^{\circ}$, the anchor cable was $33 \mathrm{~m}$ long, the anchor was $12 \mathrm{~m}$ long, and the anchor cable was prestressed at $750 \mathrm{kN}$.

Drainage holes were arranged on the surface of the first slope, with the water outlet located $4 \mathrm{~m}$ higher than the platform. Drainage holes were also arranged on the surface of the second slope, with the water outlet located $1.5 \mathrm{~m}$ higher than the platform. The water inlet of the drainage hole penetrated $1 \mathrm{~m}$ into the sliding zone and was tilted upwards by $6^{\circ}$. The strata were divided into sliding layers, gravelly soil (accumulation), strongly weathered mudstone, and moderately weathered mudstone. The specific layout of these features is shown in Figure 3, which depicts the geometric design model. 
TABle 1: Deep displacement monitoring point details.

\begin{tabular}{|c|c|c|c|}
\hline Monitoring point number & Laying depth of measuring tube $(\mathrm{m})$ & Installation date & Notes \\
\hline 1AJC08 & 19.5 & 2015.01 .11 & Damage \\
\hline 1AJC09 & 24.0 & 2015.01.07 & - \\
\hline 1AJC10 & 18.5 & 2015.01 .13 & - \\
\hline 1AJC11 & 21.5 & 2015.01.04 & - \\
\hline 1AJC12 & 18.5 & 2015.01 .02 & - \\
\hline
\end{tabular}

2.3.2. Model Boundary Conditions. The boundary conditions of the model were as follows:

(1) The $X$-axis direction of the left and right boundaries of the model is a constraint boundary. Thus, $u=0$, where $u$ is the displacement in the $X$ direction, $v$ is the displacement in the $Y$ direction, and $w$ is the displacement in the $Z$ direction.

(2) The $Z$-axis direction of the front and back boundaries of the model is a constraint boundary. Thus, $w=0$.

(3) The upper boundary of the model is set as a free boundary and no constraint is given.

The water head at the boundary node on the right was $80 \mathrm{~m}$ and that on the left was $30 \mathrm{~m}$. The head of the slope drainage node was at 0 and was a pressure head. The steadystate seepage calculation conditions were designed to obtain pore water pressure, which was then exerted to the three working conditions of slope excavation, primary support construction, and secondary support construction.

The Mohr-Coulomb elastoplastic strength criterion was used in the calculation. The initial stress is predominantly the stress from the self-weight of the geological formation. Based on the above assumptions and considerations, a model with a length, width, and height of $150 \times 1 \times 80 \mathrm{~m}$, respectively, was established. The model had a total of 11343 units and 22841 nodes, as shown in Figure 4.

2.3.3. Process Analysis. Both the state of a slope management project and the process of developing and modelling the project are important. Slope management projects rarely have engineering accidents at the time of completion or operation, but most of them have issues during construction. To address this discrepancy, we propose steady-state seepage superposition calculations and a slope-supporting process analysis method. The simulation is based on the calculation and analysis of four operating conditions: seepage calculation, slope excavation, first support construction stage, and second support construction stage. An overview of the process is shown in Figure 5.

2.3.4. Initial Parameter Determination. The initial parameters for the concrete and anchor cables were determined according to the definitions provided by the construction code. The physical and mechanical parameters of the rock and soil layer were determined by geotechnical tests and verified using the key data self-verification methods (see
Section 2.3.5 for details). Tables $2-4$ list the parameters required for the calculation model.

2.3.5. Simulation Parameter Verification. Current slope stability analyses and quantitative calculations are mainly determined by several key geotechnical parameters, which has been a contentious issue in this field. Parameters are currently determined by geotechnical testing, statistical inference from data obtained from many similar strata, or by determination from empirical data. Each of these methods has its shortcomings. Since the parameters obtained by geotechnical testing differ from the actual project, they typically need to be revised. Parameters determined from statistical data are only applicable to ordinary strata and require the accumulation of a lot of engineering data. Empirical data are convenient to use but lack robustness. In addition, all three parameter selection methods are unsuitable for special geological environments as their universality is poor. Thus, a robust method that can use field monitoring data to self-verify the main parameters is critical to the sustainable development of slope support engineering projects that rely on traditional theoretical calculations and finite element analysis.

This study proposes and uses deep displacement monitoring data and $P$ value inspection methods to check simulation parameters. As we all know, the choice of physical and mechanical parameters must be as reasonable as possible. However, there are many potential uncertain factors (including simplifying soil and rock to ideal homogeneous materials, data collection, processing and conversion, and so on). Therefore, when the parameter selection basis is not convincing, the data obtained through monitoring are used to check the initial simulation trial calculation results. When the deviation between the result obtained by the simulation trial calculation and the monitoring value is within a certain range $(P>0.01)$, it is considered that the physical and mechanical parameters selected by the calculation model are reasonable. After that, perform simulation calculations for other working conditions.

\section{Results}

3.1. Deep Displacement Monitoring. The deep displacement monitoring curves for two monitoring points (\#9: IAJC09 and \#12: IAJC12) are shown in Figure 3.

From Figure 6, it can be seen that monitoring points \#9 (1AJC09) and \#12 (IAJC12) have obvious intermediatelevel displacements. At monitoring point \#9 (1AJC09), the 


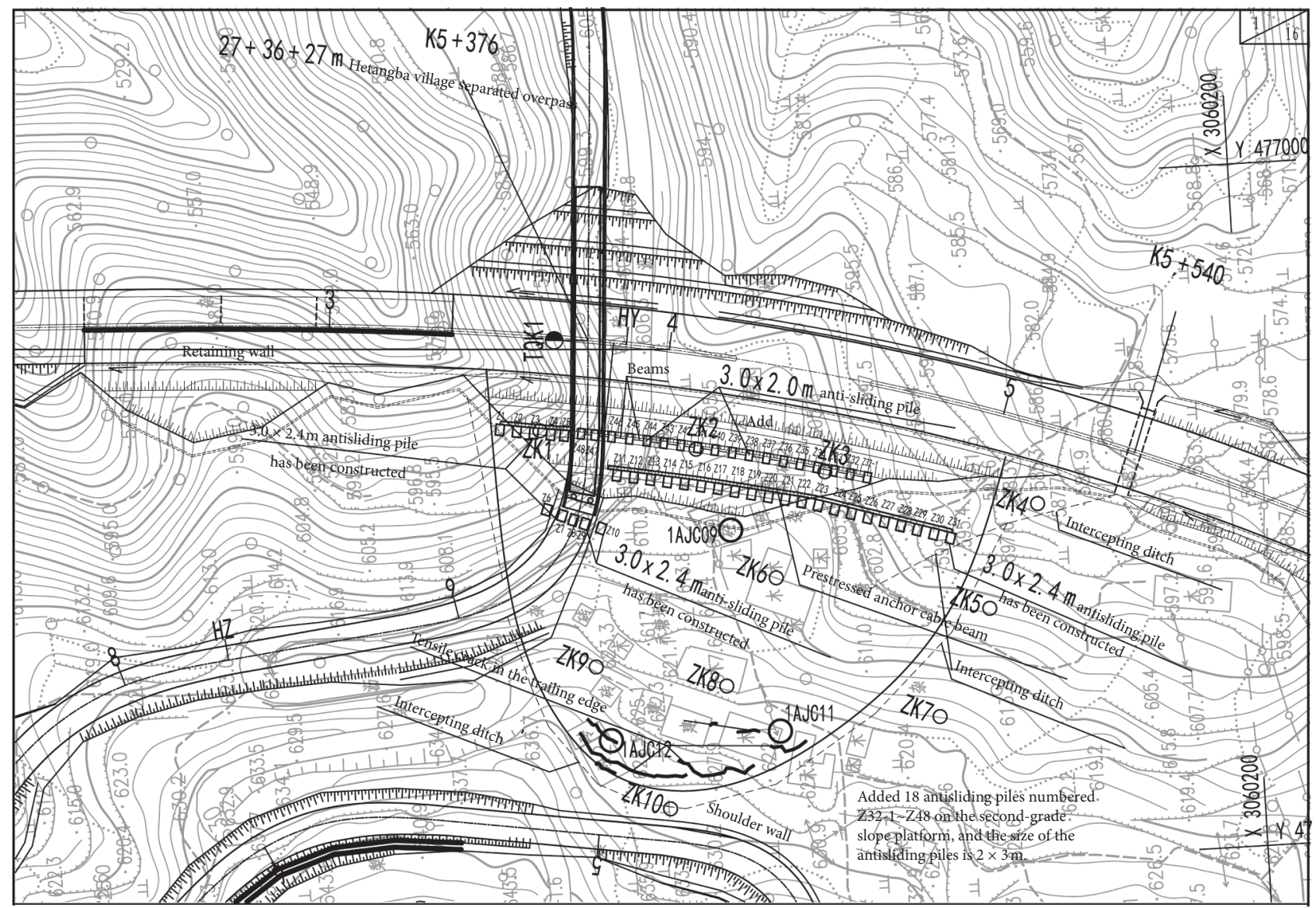

FIgURE 1: Schematic of deep hole displacement monitoring locations.

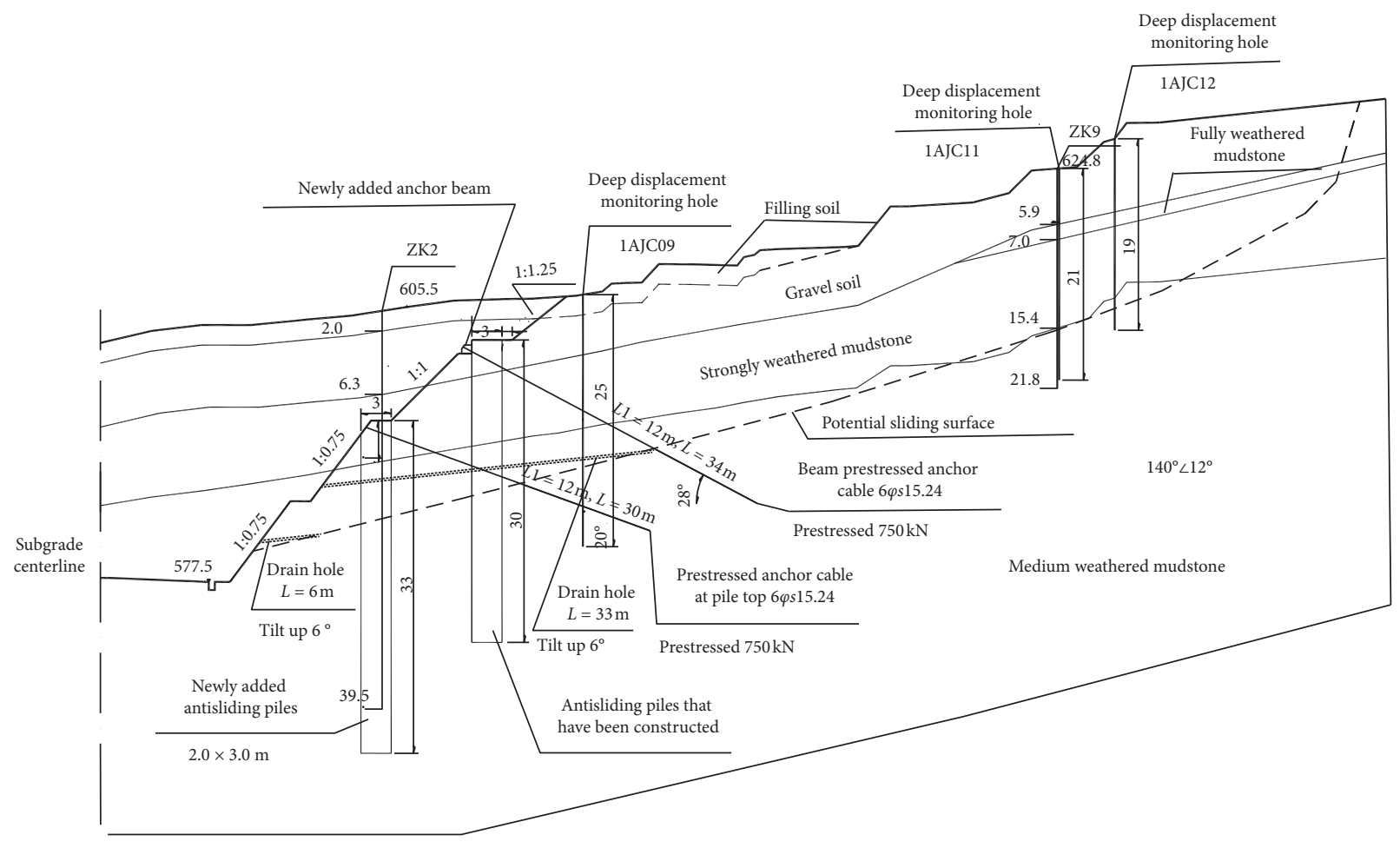

Figure 2: Cross-sectional view of the slope at K5 +420 . 


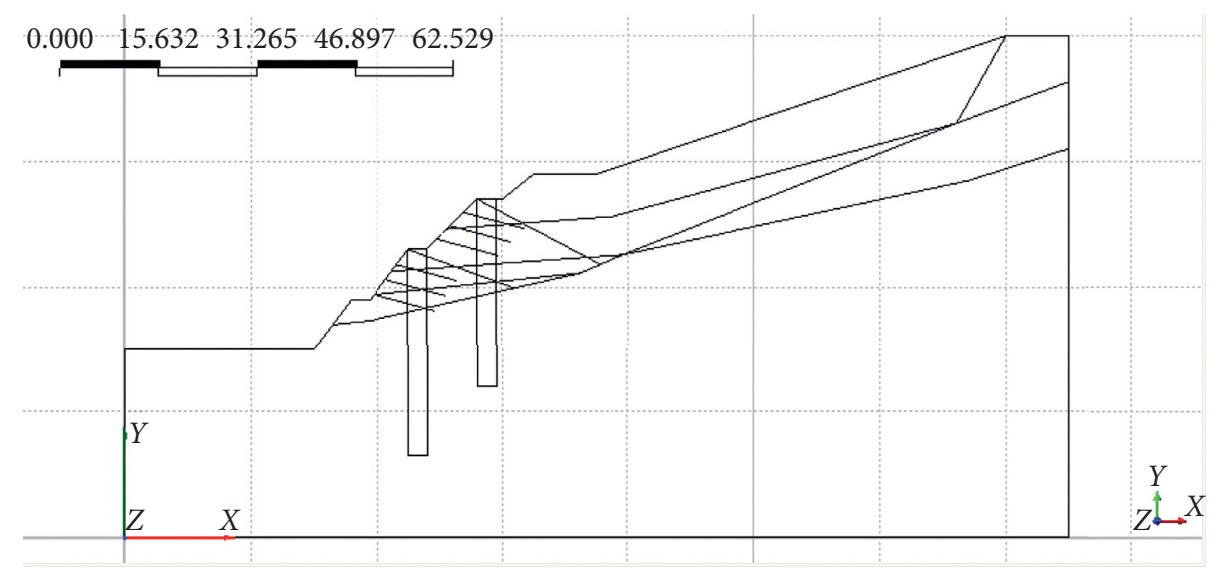

Figure 3: Geometric schematic of the K5 +420 slope section used for modelling.

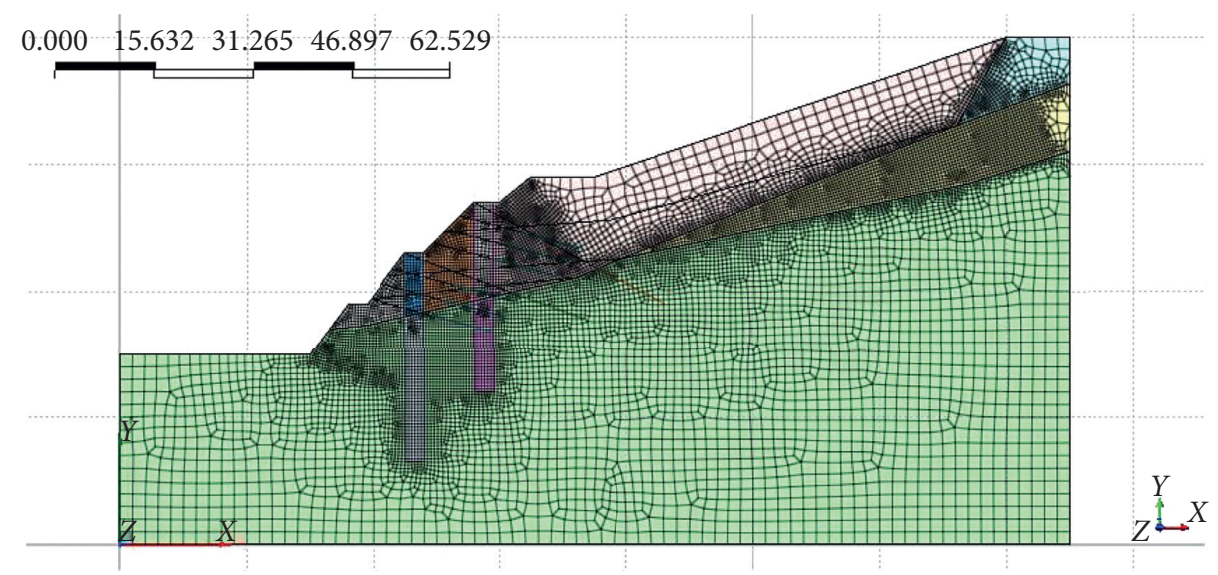

Figure 4: Mesh model diagram of the K5 + 420 slope section.

sliding surface was located 13.0-14.0 m deep. As of August 29, 2015 (prior to the second stage of construction), the maximum cumulative displacement of the sliding surface was $9.85 \mathrm{~cm}$. The maximum cumulative displacement at monitoring point \#9 over the entire monitoring period (January 13, 2015, to the end of second support construction) was $12.6 \mathrm{~cm}$. At monitoring point \#12 (1AJC12), the depth of the sliding surface was $6.0-8.0 \mathrm{~m}$. As of August 29, 2015, the maximum cumulative displacement at the sliding surface was $10.9 \mathrm{~cm}$, and the maximum cumulative displacement over the entire monitoring period was $15.6 \mathrm{~cm}$.

3.2. Parameter Verification. From Figure 7, it can be seen that the maximum horizontal displacement of the formation after the construction of the initial support is $0.102191 \mathrm{~m}$. The data obtained before the second support was constructed on August 29, 2015, at the \#9 and \#12 deep displacement monitoring holes located on section $\mathrm{K} 5+420$ were selected for the verification of the simulation parameters.

Figure 8 shows the comparison between the actual displacement monitoring data and the simulation displacement data. $P$ value testing was used to compare the results: for monitoring hole $9, P=0.039>0.01$, whereas for monitoring hole $12, P=0.793>0.01$. This result verified that the parameters that were initially selected for the simulation are valid.

\subsection{Simulation Analysis}

3.3.1. Initial Support Analysis Disregarding Steady-State Seepage. A stress analysis of the antislide pile after the construction of the initial support was performed, and the results are shown in Figure 9.

Figure 9(a) shows that after the initial support was constructed, without considering steady-state seepage, the maximum axial force on the antislide pile was $-4.205076 e 3 \mathrm{kN}$, which occurs near the bottom-third of the pile. The maximum axial stress on the antislide pile was $-5.990383 e 2 \mathrm{kN} / \mathrm{m}^{2}$, and the location of the maximum stress is consistent with that of the maximum axial force (Figure 9(b)). Figure 9(c) shows that the maximum shear force on the antislide pile is $-1.887276 e 3 \mathrm{kN}$. The shear force changes direction at the interface of the sliding surface and the bedrock. Figure $9(\mathrm{~d})$ shows that the maximum bending moment of the antislide pile is $-1.28113 e 4 \mathrm{kN} \cdot \mathrm{m}$ and that this occurs at approximately the midpoint of the pile. 


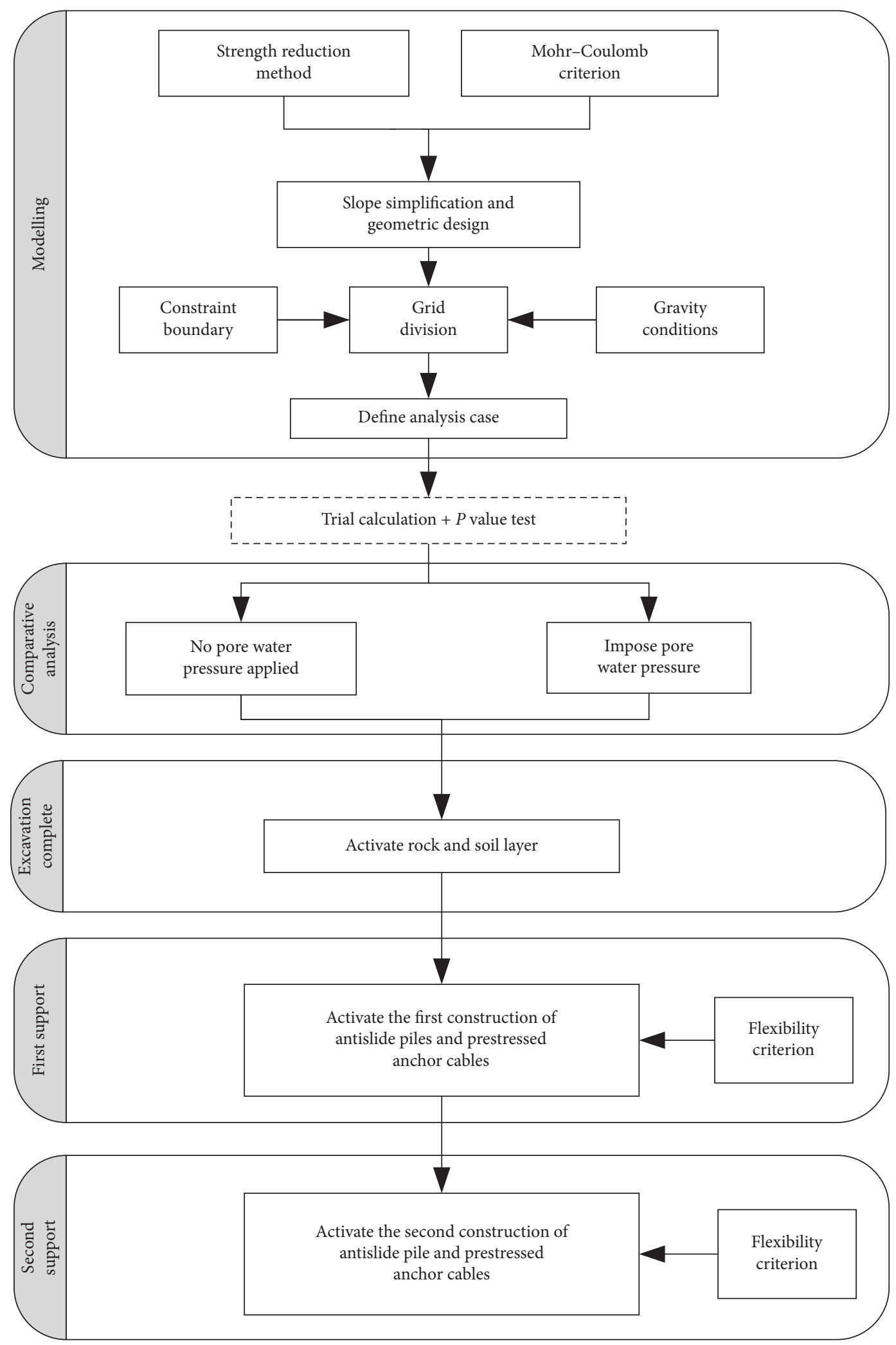

FIgURE 5: Modelling and calculation process flowchart.

Figure 10 shows the results of the stress analysis of the prestressed anchor cable after the initial support was constructed, without considering steady-state seepage. The axial force of the prestressed anchor cable is $8.36198 e 2 \mathrm{kN}$. The maximum axial force is located at the junction of the anchoring section and the free section of the upper two cable 
TABLE 2: Rock and soil parameters.

\begin{tabular}{|c|c|c|c|c|c|c|c|c|}
\hline Soil layer & $\begin{array}{c}\text { Elastic } \\
\text { modulus } \\
\left(\mathrm{kN} / \mathrm{m}^{2}\right)\end{array}$ & $\begin{array}{l}\text { Poisson's } \\
\text { ratio }\end{array}$ & $\begin{array}{l}\text { Angle of } \\
\text { internal } \\
\text { friction }\left(^{\circ}\right)\end{array}$ & $\begin{array}{c}\text { Cohesion } \\
\text { forces } \\
\left(\mathrm{kN} / \mathrm{m}^{2}\right) \\
\end{array}$ & $\begin{array}{c}\text { Natural unit } \\
\text { weight } \\
\left(\mathrm{kN} / \mathrm{m}^{3}\right)\end{array}$ & $\begin{array}{c}\text { Saturated unit } \\
\text { weight } \\
\left(\mathrm{kN} / \mathrm{m}^{3}\right)\end{array}$ & $\begin{array}{l}\text { Permeability } \\
\text { coefficient } \\
(\mathrm{m} / \mathrm{d})\end{array}$ & $\mathrm{SPT}(\mathrm{N})$ \\
\hline Sliding layer & 160000 & 0.28 & 10.5 & 12 & 18.0 & 18.5 & 0.10 & 18 \\
\hline Gravel soil & 80000 & 0.30 & 15.0 & 30 & 17.5 & 18.0 & 0.10 & 33 \\
\hline $\begin{array}{l}\text { Strongly weathered } \\
\text { mudstone }\end{array}$ & 200000 & 0.25 & 19.0 & 50 & 19.5 & 20.0 & 0.20 & - \\
\hline $\begin{array}{l}\text { Moderately } \\
\text { weathered } \\
\text { mudstone }\end{array}$ & 1200000 & 0.20 & 28.0 & 310 & 20.5 & 21.0 & 0.02 & - \\
\hline
\end{tabular}

TABLE 3: Mechanical parameters of the support structures.

\begin{tabular}{lccc}
\hline Structure & Elastic modulus $\left(\mathrm{kN} / \mathrm{m}^{2}\right)$ & Unit weight $\left(\mathrm{kN} / \mathrm{m}^{3}\right)$ & Poisson's ratio \\
\hline Antislide pile & $2.40 E 7$ & 25.0 & 0.3 \\
Anchor & $2.05 E 8$ & 78.5 & 0.2 \\
\hline
\end{tabular}

TABLE 4: Parameters of the anchor cables.

\begin{tabular}{|c|c|c|c|c|c|c|c|}
\hline \multicolumn{2}{|l|}{ Anchor cable classification } & $\begin{array}{c}\text { Slope spacing } \\
(\mathrm{m})\end{array}$ & $\begin{array}{c}\text { Total length } \\
(\mathrm{m})\end{array}$ & $\begin{array}{l}\text { Anchoring section } \\
(\mathrm{m})\end{array}$ & $\begin{array}{c}\text { Prestress } \\
(\mathrm{kN})\end{array}$ & $\begin{array}{c}\text { Tilt angle } \\
\left({ }^{\circ}\right)\end{array}$ & $\begin{array}{c}\text { Aperture } \\
(\mathrm{mm})\end{array}$ \\
\hline \multirow{6}{*}{ Initial support } & 1 & 3 & 20 & 10 & 500 & 20 & 130 \\
\hline & 2 & 3 & 20 & 10 & 500 & 20 & 130 \\
\hline & 3 & 3 & 20 & 10 & 500 & 20 & 130 \\
\hline & 1 & 3 & 20 & 10 & 500 & 20 & 130 \\
\hline & 2 & 3 & 20 & 10 & 500 & 20 & 130 \\
\hline & 3 & 3 & 20 & 10 & 500 & 20 & 130 \\
\hline \multirow{2}{*}{ Secondary support } & Level 3 & - & 33 & 11 & 750 & 28 & 130 \\
\hline & Level 2 & - & 33 & 12 & 750 & 20 & 130 \\
\hline
\end{tabular}

layers on the second-level slope. Moreover, for the two sets of prestressed anchor cables on the second- and third-level slopes, which have three layers each, the axial force of the upper two cable layers is significantly greater than that of the bottom layer. The maximum axial stress of the prestressed anchor cable is $4.73191 \mathrm{e} 4 \mathrm{kN} / \mathrm{m}^{2}$, and the axial stress distribution position and characteristics are consistent with those of the axial force.

3.3.2. Initial Support Analysis considering Steady-State Seepage. Figure 11 shows the results of a stress analysis of the first antislide pile considering the effects of steady-state seepage.

Analysis of Figure 11(a) shows that the maximum axial force of the antislide pile is $-4.27074 e 3 \mathrm{kN}$ when steady-state seepage is considered and that the maximum occurs near the bottom-third of the pile. Figure 11(b) shows that the maximum axial stress on the antislide pile is $-5.93158 e 2 \mathrm{kN} /$ $\mathrm{m}^{2}$ and that the location of the maximum stress is consistent with the axial force. Figure 11(c) shows that the maximum shear resistance of the antislide pile is $-1.887355 e 3 \mathrm{kN}$. The direction of the shear force changes at the sliding surface at the interface of the bedrock. The maximum bending moment of the antislide pile is $-1.26005 e 4 \mathrm{kN} \cdot \mathrm{m}$, which occurs near the midpoint of the pile.

After considering the effects of steady-state seepage, the maximum axial force on the first antislide pile increases by
$0.47 \%$, and the maximum axial stress increases by $0.51 \%$. There is almost no change in the location of maximum axial force or stress. Furthermore, the maximum shear force on the antislide pile increases by $0.05 \%$ and the maximum bending moment decreases by $1.56 \%$ when considering steady-state seepage effects. There is no obvious change in the distribution of the maximum shear force or bending moment. Thus, steady-state seepage generally has little effect on the forces and stress on the antislide pile of the first support.

Figure 12 shows a stress analysis of the prestressed anchor cable considering steady-state seepage after the construction of the initial support. The maximum axial force of the prestressed anchor cable is $9.29907 e 2 \mathrm{kN}$, and the location and characteristics of the maximum force distribution are the same as when steady-state seepage is not considered. The maximum axial stress of the prestressed anchor cable is $5.26220 e 4 \mathrm{kN} / \mathrm{m}^{2}$, and the axial stress distribution position and characteristics are consistent with axial force.

After considering the effects of steady-state seepage, the maximum axial force of the prestressed anchor cable increases by $11.22 \%$ and the maximum axial stress increases by $11.20 \%$. There is no obvious change in the distribution of the maximum axial force or axial stress. Thus, steady-state seepage has a significant influence on the prestressed anchor cables of the first support structure, which should be carefully considered in determining the appropriate prestress. 


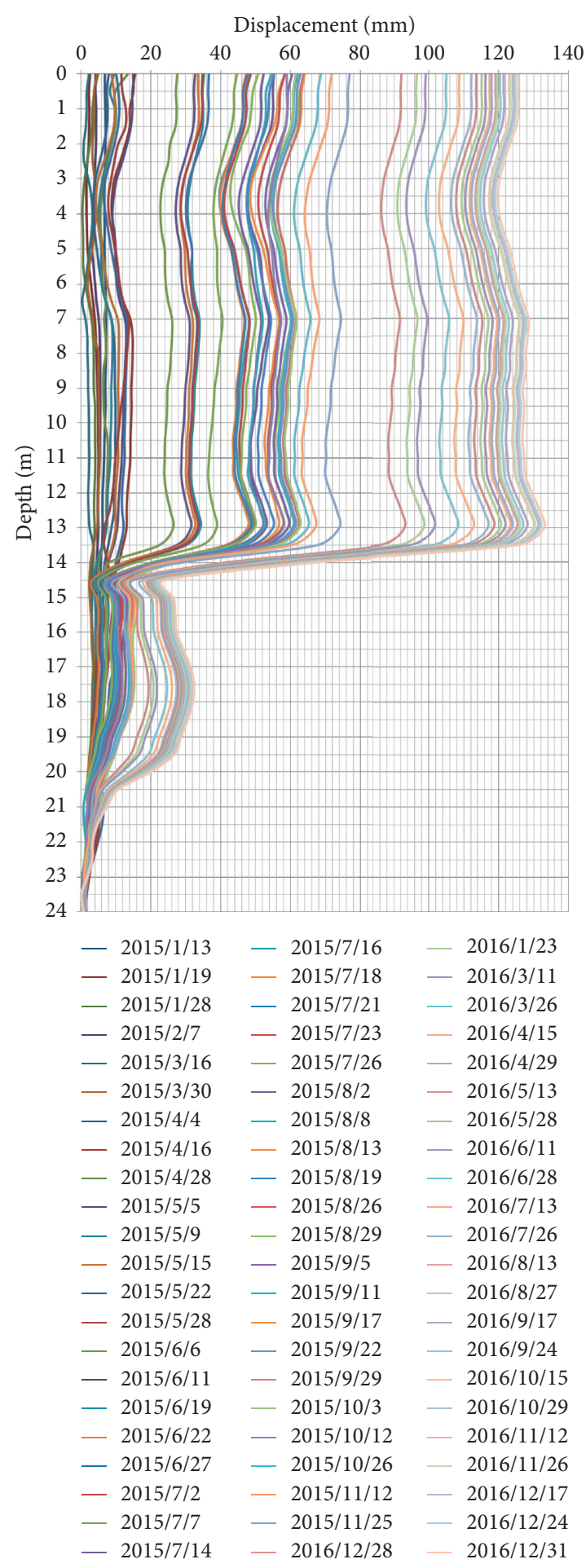

(a)

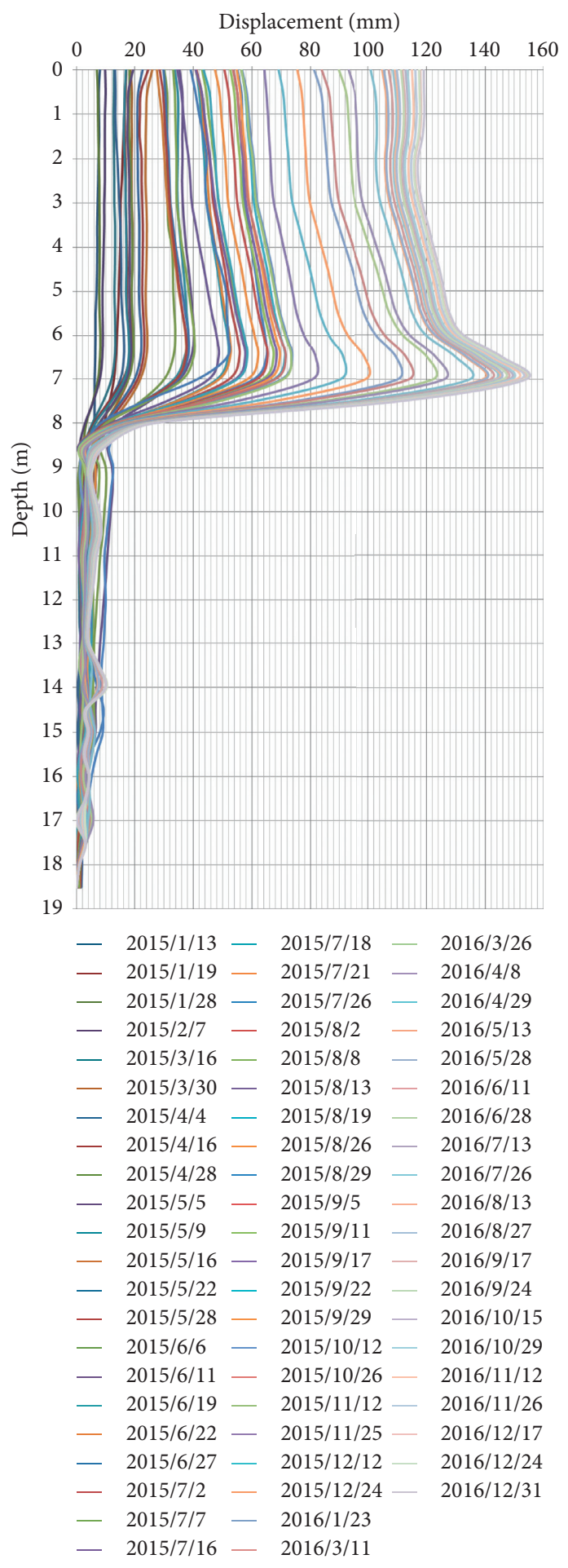

(b)

FIGURE 6: (a) 1AJC09 cumulative total displacement curve. (b) 1AJC12 cumulative total displacement curve.

3.3.3. Analysis of the Secondary Support Structure Disregarding Steady-State Seepage. Figure 13 shows the results of a stress analysis for the secondary antislide pile.

Figure 13(a) shows that the maximum axial force on the antislide pile is $-5.96582 e 3 \mathrm{kN}$, and the extreme value appears near the bottom $1 / 3$ of the newly installed antislide pile. The maximum axial stress on the antislide pile is $-8.28586 e 2 \mathrm{kN} / \mathrm{m}^{2}$, and the location of the maximum stress is consistent with the axial force distribution (Figure 13(b)). Figure 13(c) shows that the maximum shear forces on the antislide piles are $-1.444887 e 3 \mathrm{kN}$, respectively, and that the extreme value appears near the first $1 / 3$ 


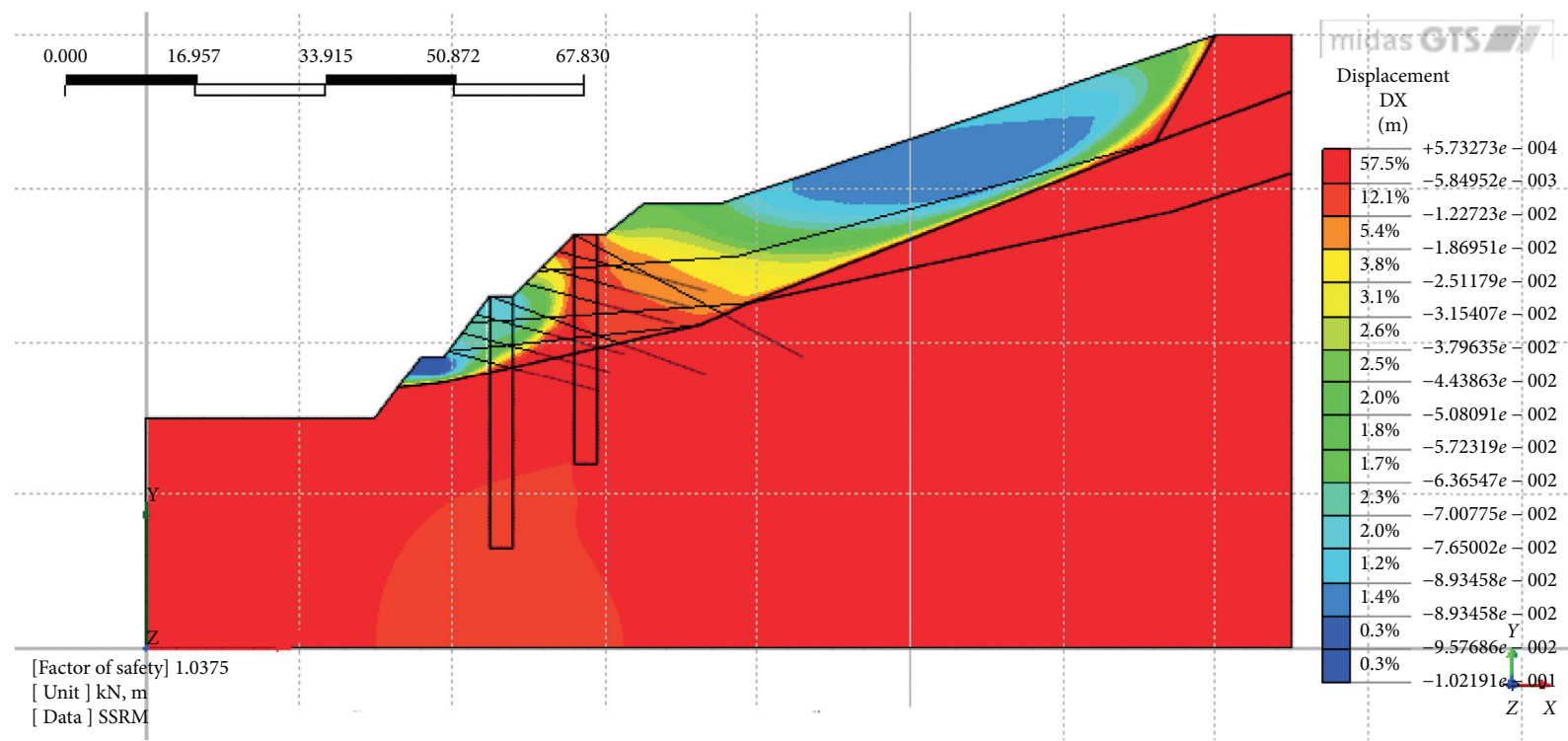

FIgURE 7: Horizontal displacement of the formation after construction of the initial support.

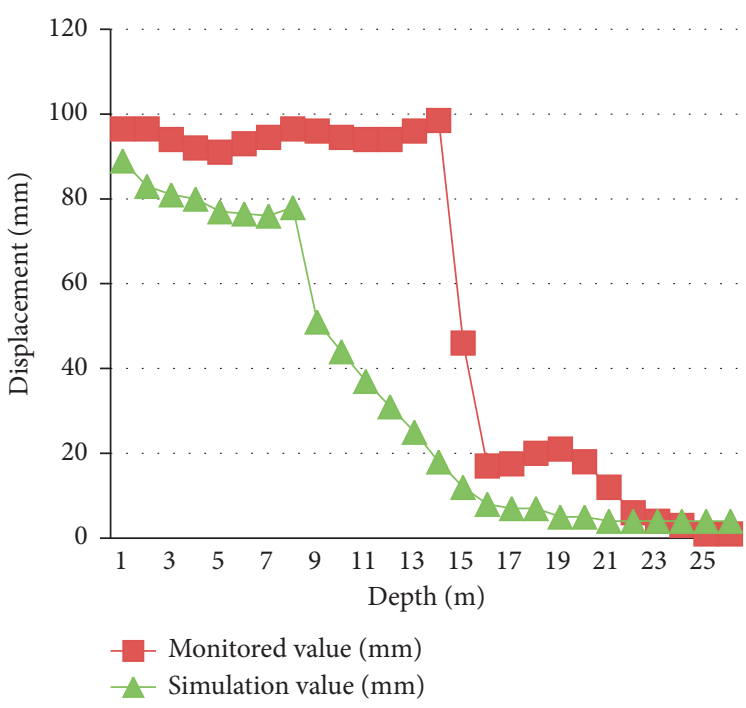

(a)

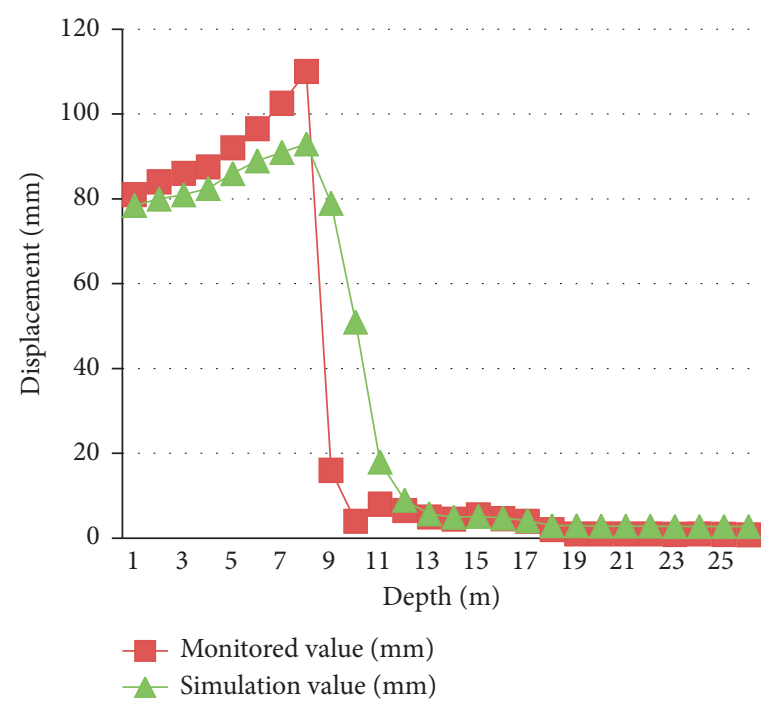

(b)

FIGURE 8: Actual horizontal displacement monitoring data compared to simulation data. (a) Location of hole $9(P=0.039)$. (b) Location of hole $12(P=0.793)$.

position of the bottom end of the first antislide pile. The shear force changes direction at the interface between the sliding surface and the bedrock and behaves as though there were multiple concurrent direction changes. The maximum bending moment of the antislide pile is $-1.00180 \mathrm{e} 4 \mathrm{kN} \cdot \mathrm{m}$, which occurs at the near midpoint of the initial support antislide pile.

Figure 14 shows the results of a stress analysis of the prestressed anchor cable without considering steady-state seepage. Figure 14(a) shows that after the second support is constructed, the maximum axial force of the prestressed anchor cable is $9.17205 e 2 \mathrm{kN}$. In this case, the maximum force occurs at the junction of the anchoring section and the free section of the prestressed anchor cable along the third-grade slope. The axial force of the upper two layers of prestressed cables along the second-and third-grade slopes from the initial construction is still significantly greater than the first layer of cable. The maximum axial stress of the prestressed anchor cable is $5.19032 e 4 \mathrm{kN} / \mathrm{m}^{2}$, and the axial stress distribution position and characteristics are consistent with the axial force.

\subsubsection{Analysis of the Secondary Support Structure considering} Steady-State Seepage. Figure 15 shows the stress analysis of the antislide piles following construction of the secondary support, considering steady-state seepage. 


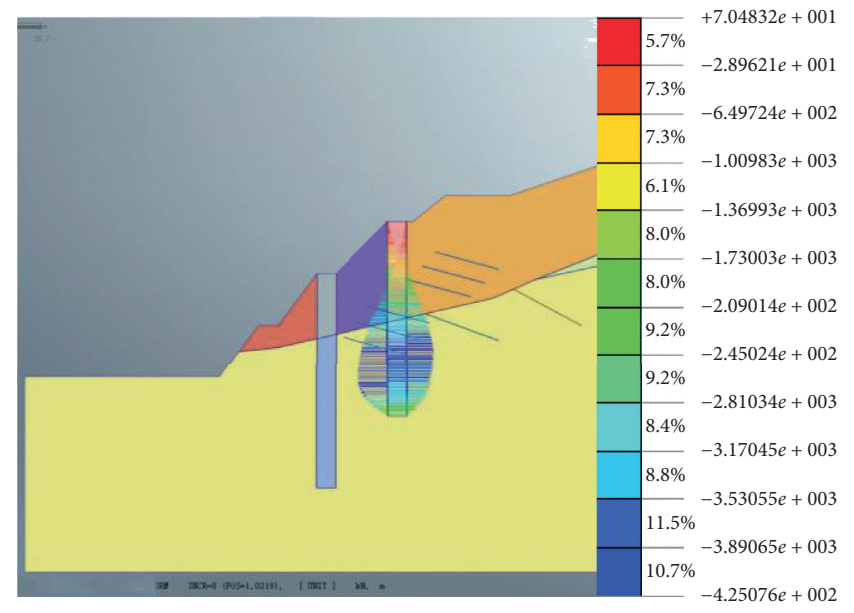

(a)

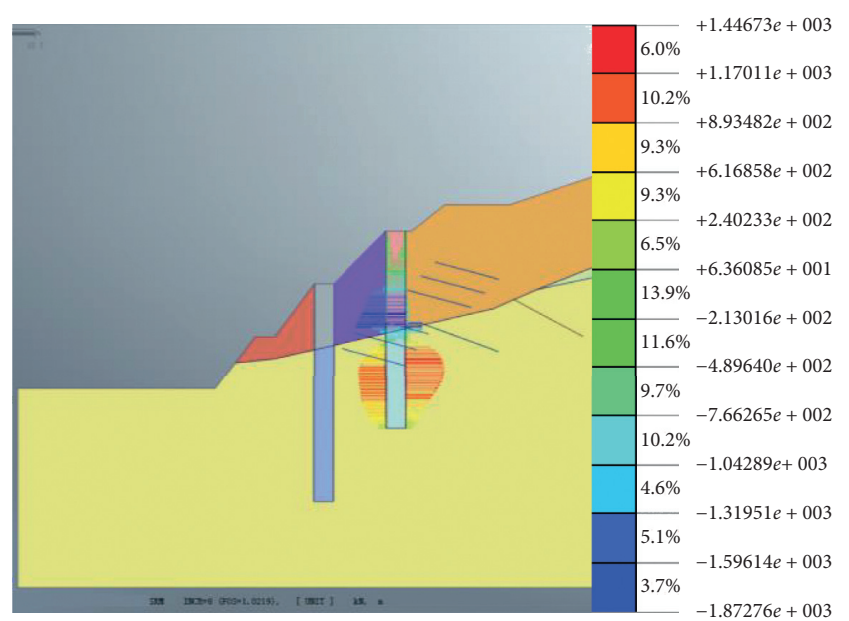

(c)

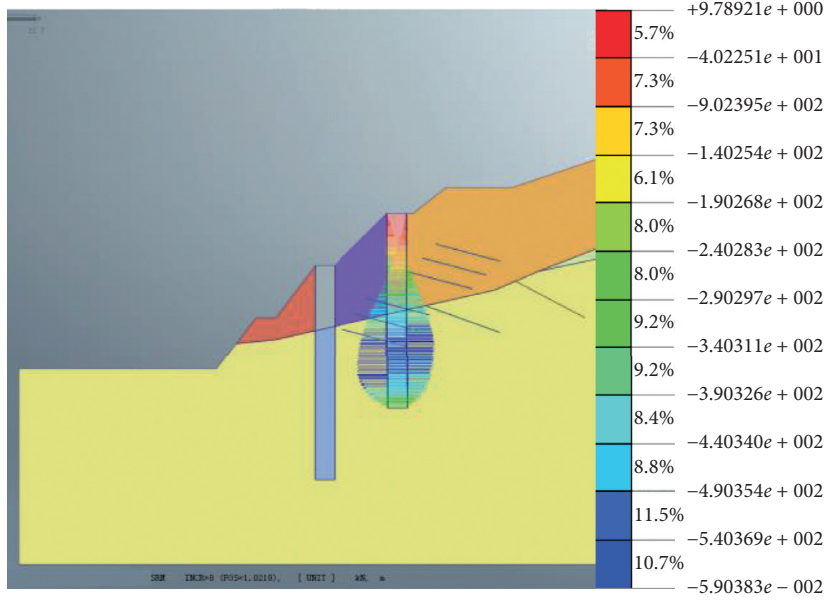

(b)

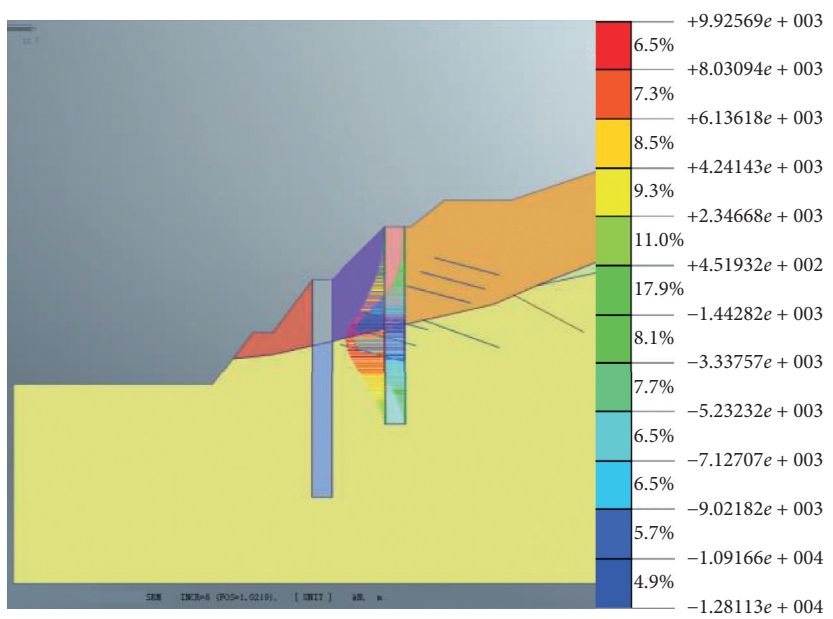

(d)

FIGURE 9: Stress cloud diagrams of antislide piles without considering steady-state seepage. Cloud maps of antislide pile: (a) axial force; (b) axial stress; (c) shear; (d) bending moment.

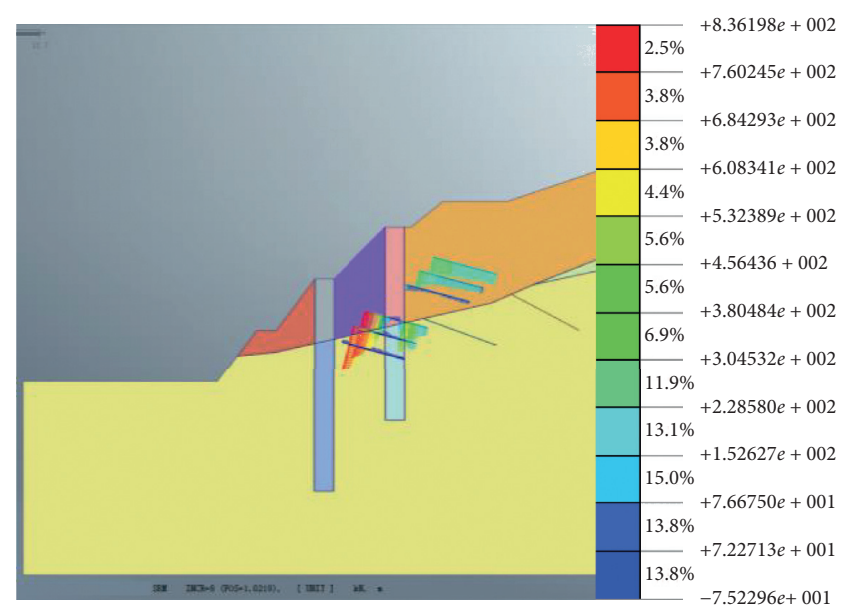

(a)

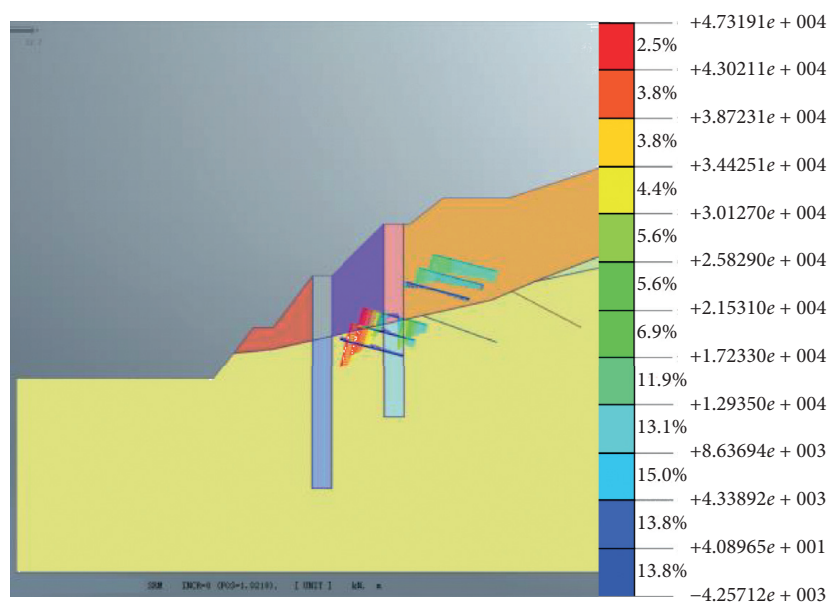

(b)

Figure 10: Cloud diagrams of the prestressed anchor cable without considering steady-state seepage. (a) Axial force cloud diagram. (b) Axial stress cloud diagram. 


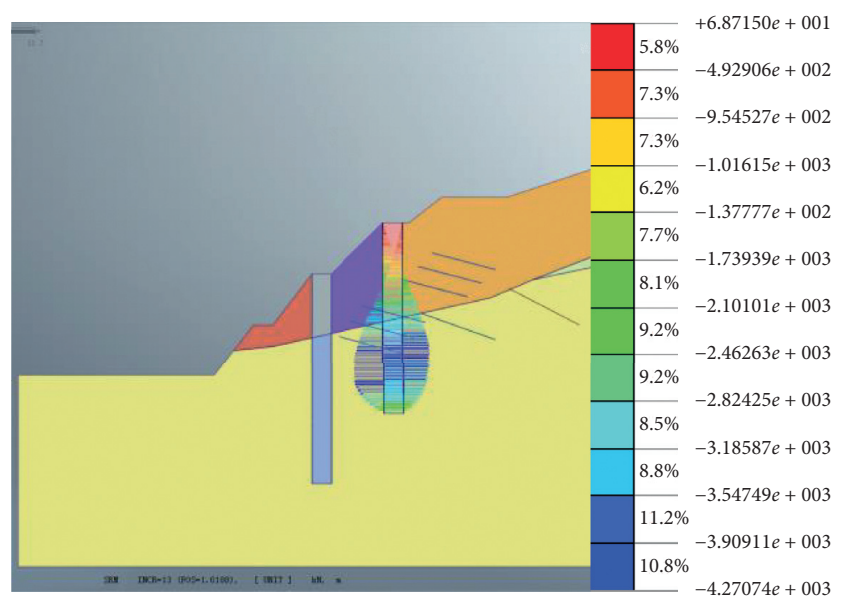

(a)

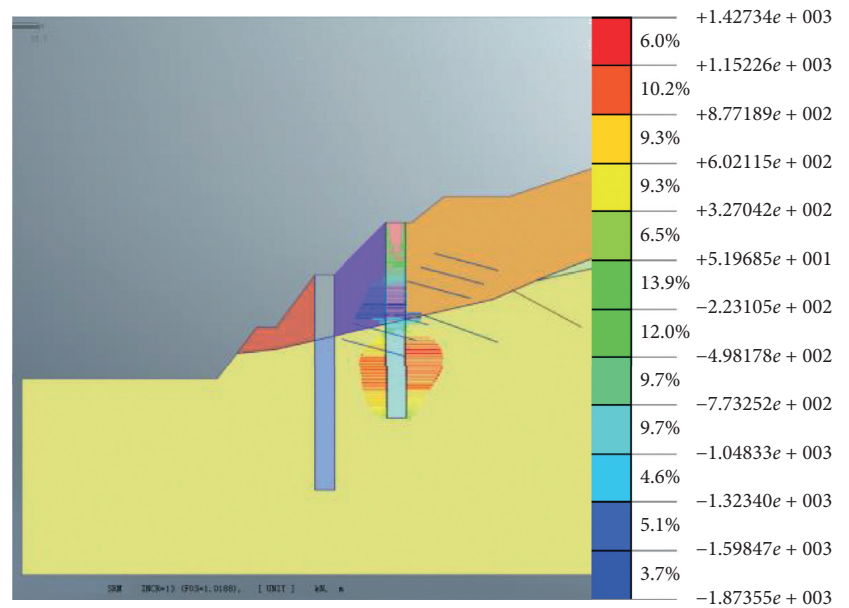

(c)

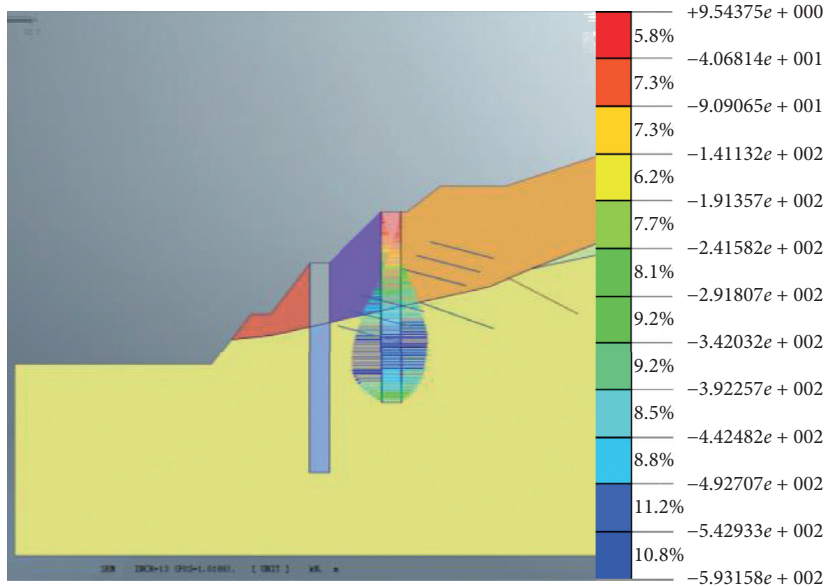

(b)

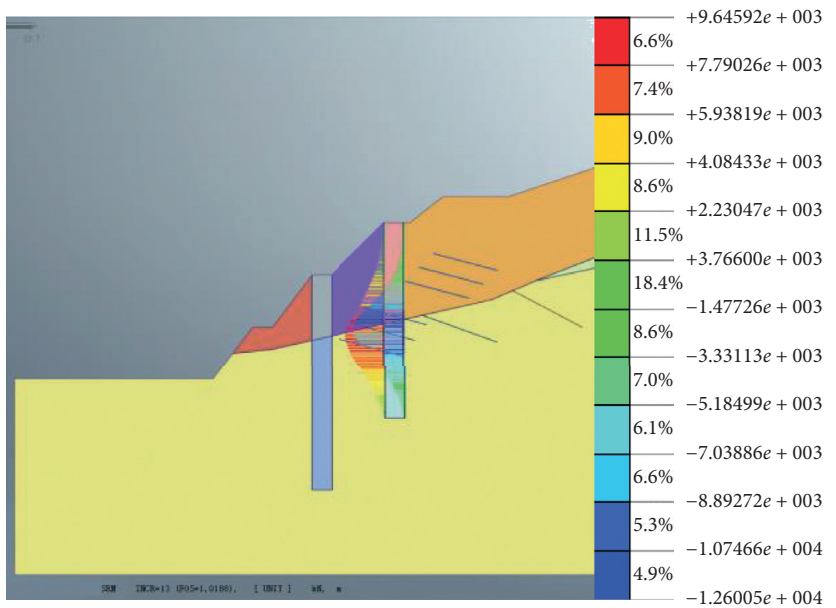

(d)

FIGURE 11: Cloud diagrams of antislide piles when considering steady-state seepage: (a) axial force; (b) axial stress; (c) shear force; (d) bending moment.

Figure 15(a) shows that the maximum axial force on the antislide pile is $-6.113164 e 3 \mathrm{kN}$ and that this maximum force occurs near the upper-third of the bottom portion of the secondary support antislide pile. The maximum axial stress on the antislide pile is $-8.51617 e 2 \mathrm{kN} / \mathrm{m}^{2}$, and the location of the maximum stress is consistent with the axial force (Figure 15(b)). Figure 15(c) shows that the maximum shear resistance of antislide piles is $-1.40366 e 3 \mathrm{kN}$, respectively, and that the maximum shear force occurs near the bottom $1 /$ 3 of the initial support of the antislide pile. The shear force changes at the interface between the sliding surface and the bedrock. The maximum bending moment of the antislide pile is $-9.37553 e 3 \mathrm{kN} \cdot \mathrm{m}$ and occurs near the midpoint of the first antislide pile.

The maximum axial force increases by $2.78 \%$, and the maximum axial stress increases by $2.78 \%$ compared to seepage effects being disregarded. However, the distribution of the axial force and stress does not change significantly after steady-state seepage is considered. Furthermore, the maximum shear resistance of the antislide pile is reduced by $3.11 \%$ and the extreme bending moment is reduced by $14.90 \%$ after the consideration of seepage effects. The distribution of the shear forces and bending moment did not change significantly. Thus, steady-state seepage has little effect on axial force and stress but has a significant effect on reducing shear stress and bending moment of the antislide pile after the construction of the secondary support.

In addition, compared to the first support alone when considering steady-state seepage, the shear force on the first antislide pile is reduced by $25.08 \%$, and the bending moment is reduced by $25.59 \%$. Thus, the secondary support provides evident resistance to sliding piles. Furthermore, the maximum shear force on the additional antislide pile in the secondary support is $-7.888869 e 2 \mathrm{kN}$, which is $56.20 \%$ of the maximum shear stress on the first antislide pile. Similarly, the bending moment of the secondary antislide pile added is $-5.59139 e 3 \mathrm{kN} \cdot \mathrm{m}$, which is only $59.63 \%$ of the maximum bending moment of the first antislide pile. This suggests that the flexural and shear resistance of the additional antislide pile contributed by the secondary support has not been maximized. 


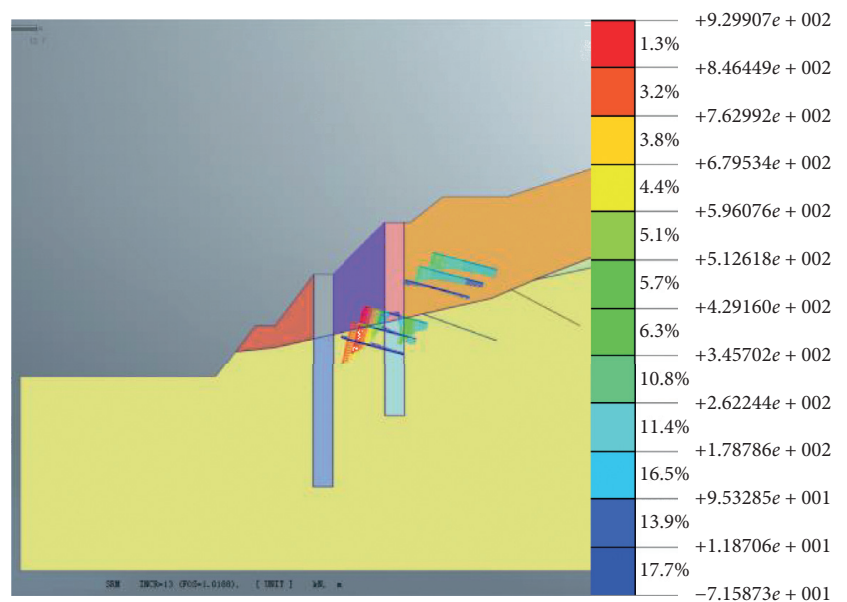

(a)

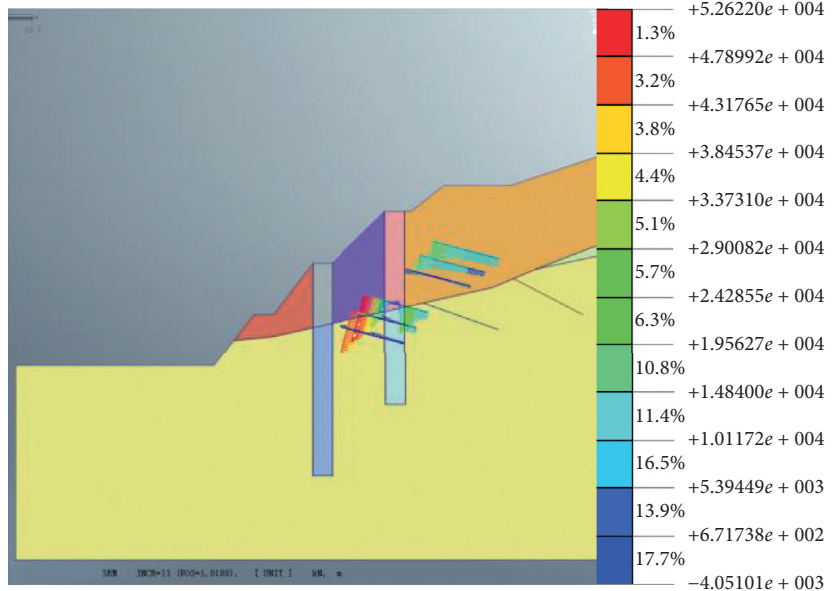

(b)

FIgURE 12: Cloud diagrams of the prestressed anchor cable considering steady-state seepage: (a) axial force; (b) axial stress.

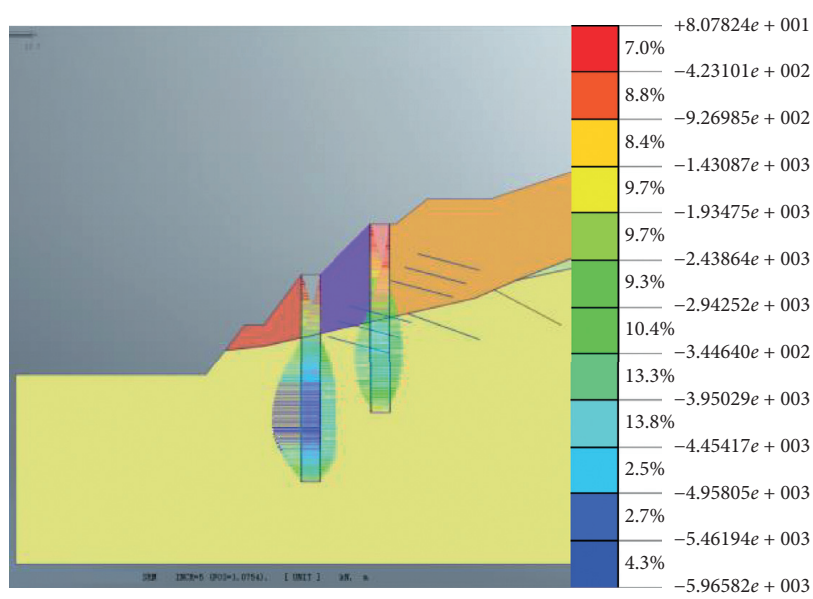

(a)

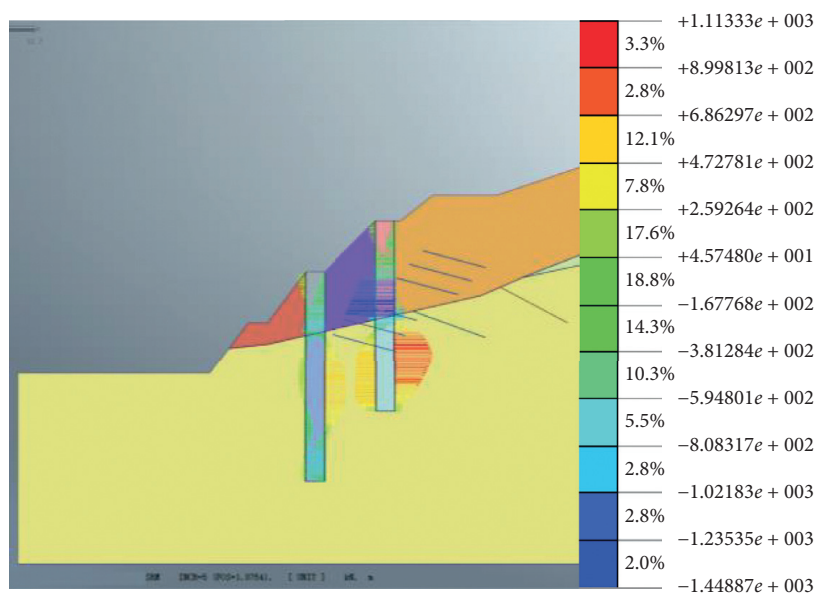

(c)

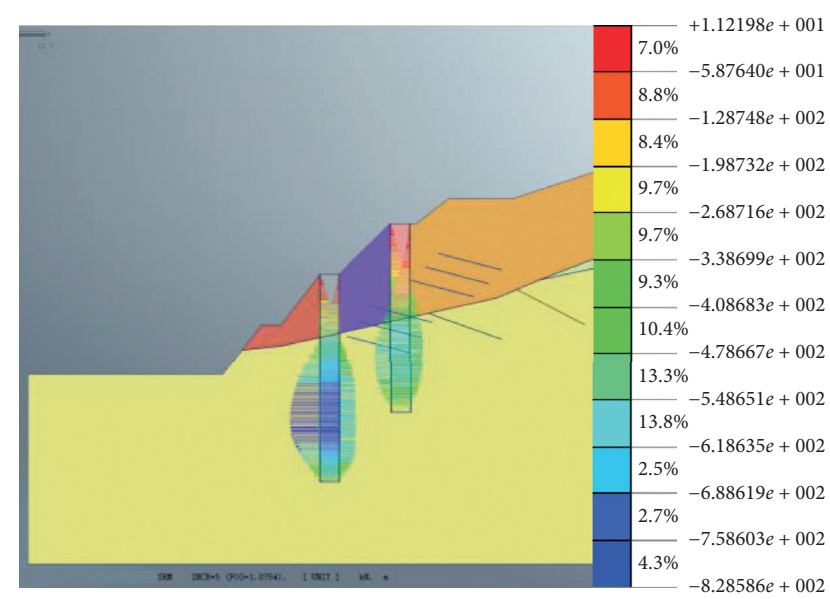

(b)

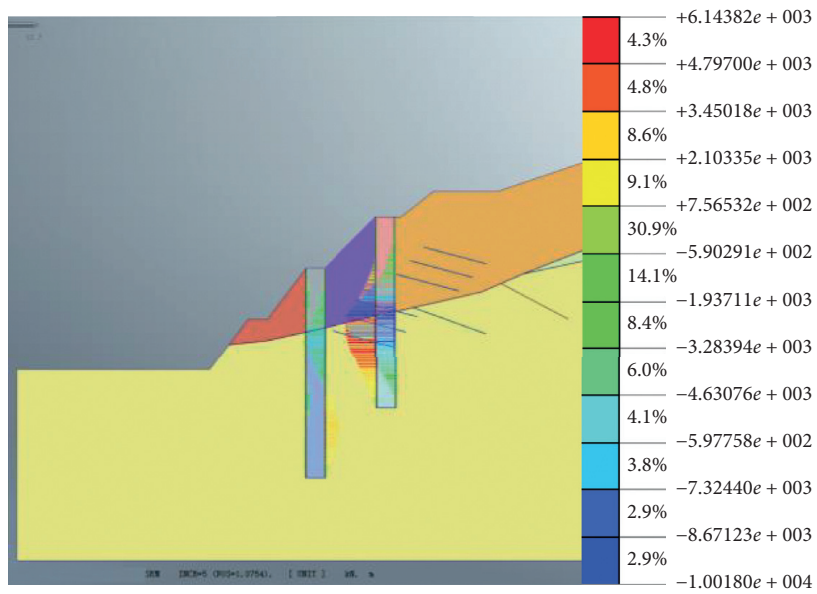

(d)

FIGURE 13: Cloud diagrams of the antislide piles without considering steady-state seepage: (a) axial force; (b) axial stress; (c) shear force; (d) bending moment. 


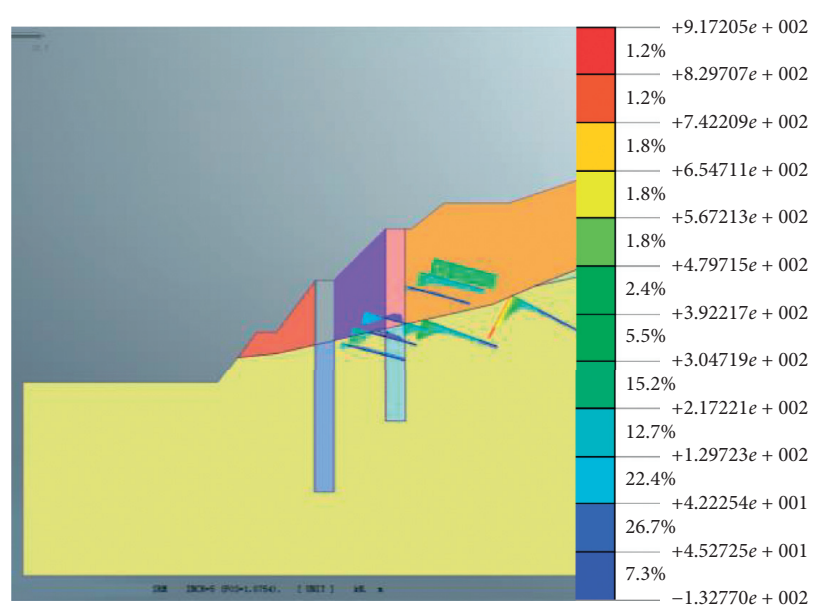

(a)

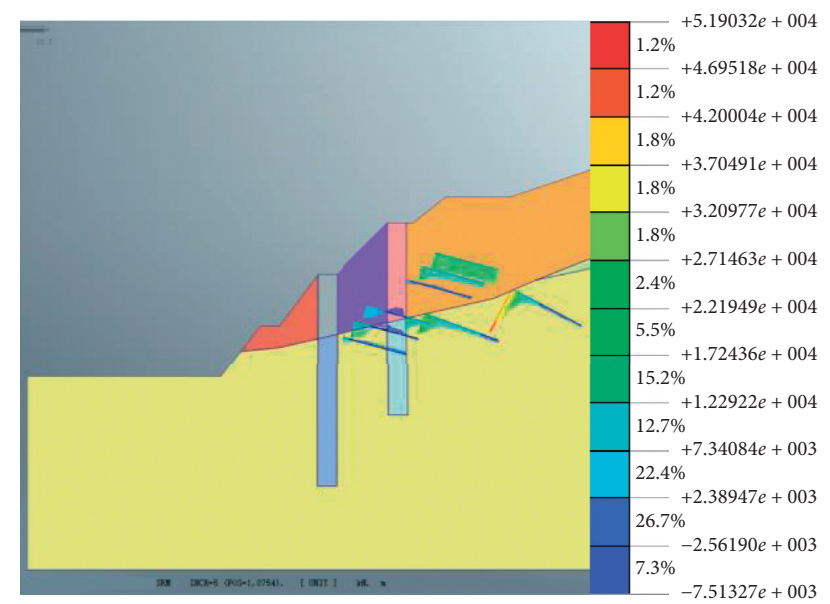

(b)

FIGURE 14: Cloud diagrams of prestressed anchor cable without considering steady-state seepage after construction of the secondary support: (a) axial force; (b) axial stress.

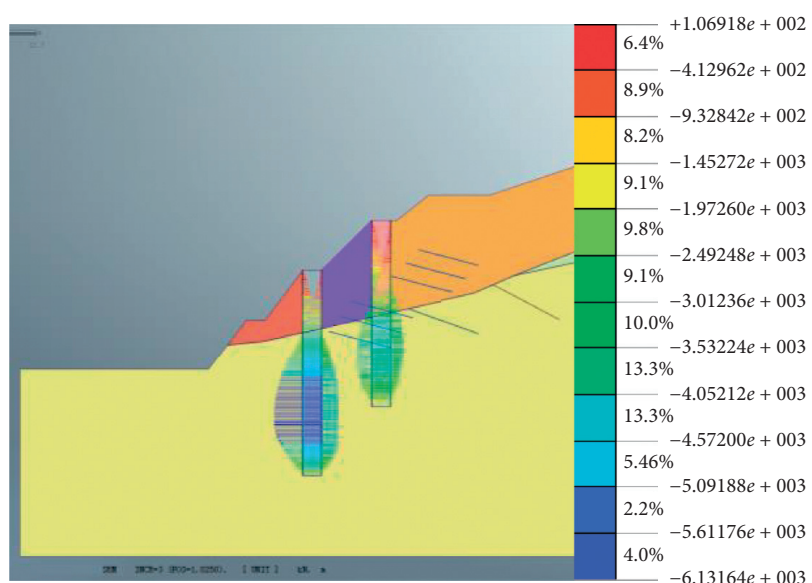

(a)

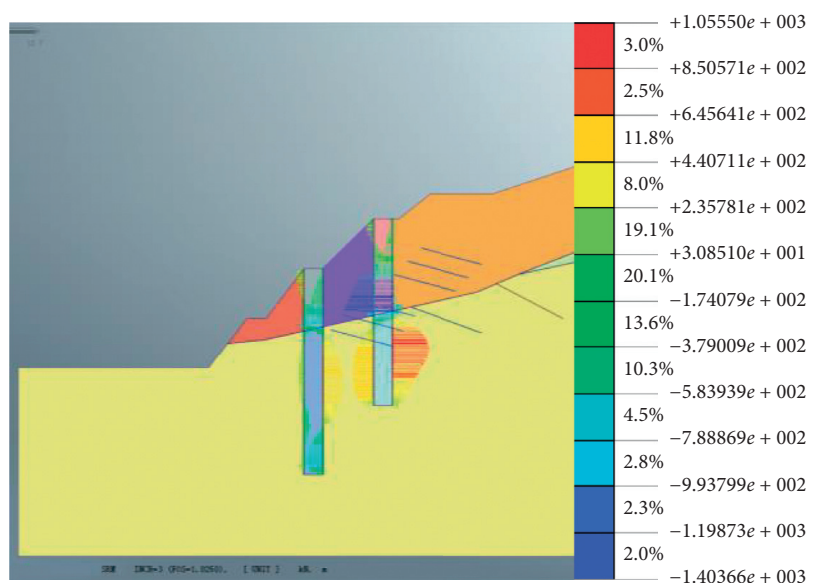

(c)

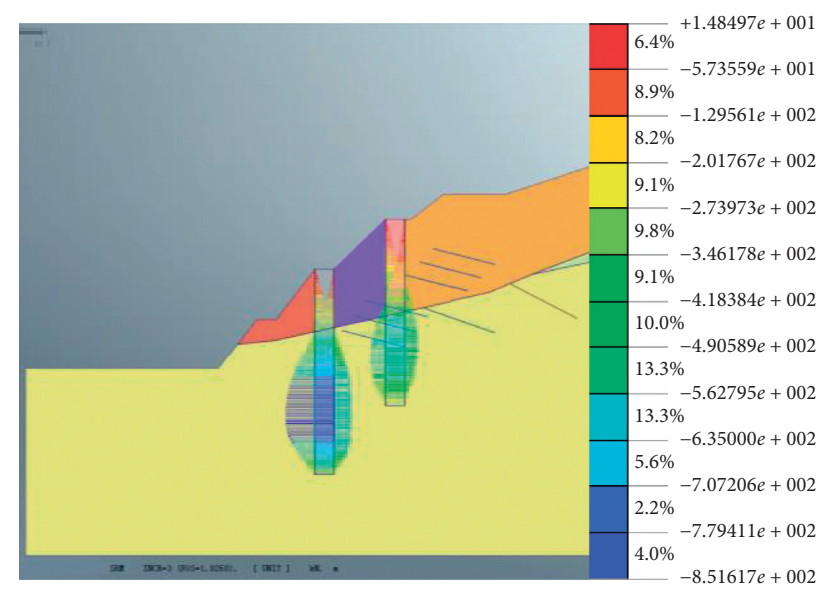

(b)

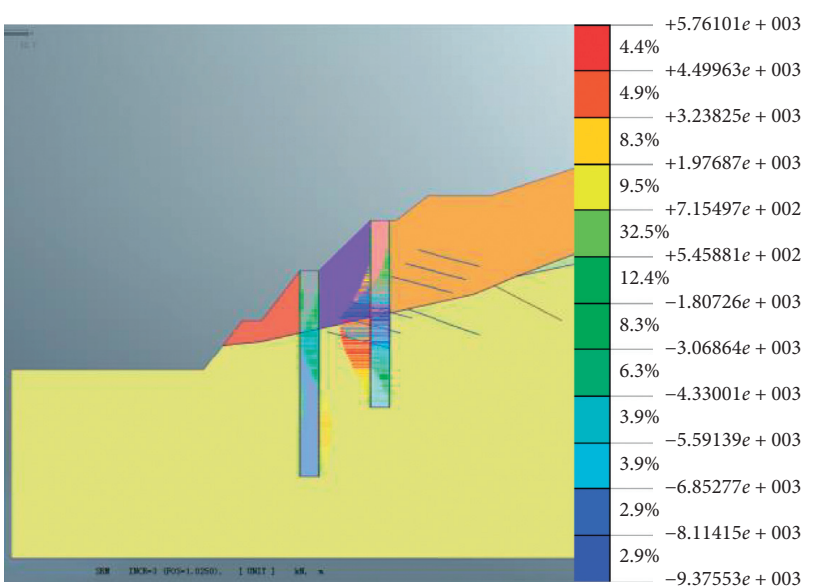

(d)

FiguRE 15: Cloud diagrams of the antislide piles when considering steady-state seepage: (a) axial force; (b) axial stress; (c) shear force; (d) bending moment. 


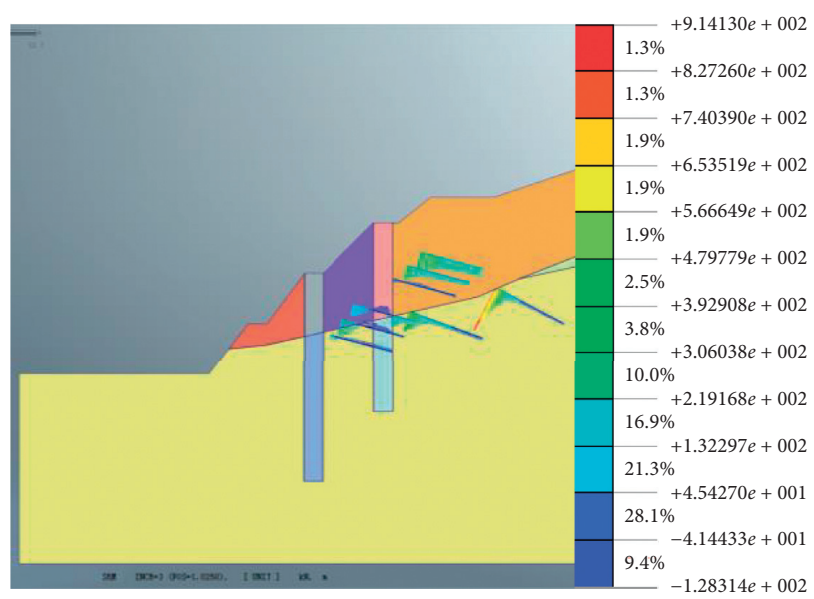

(a)

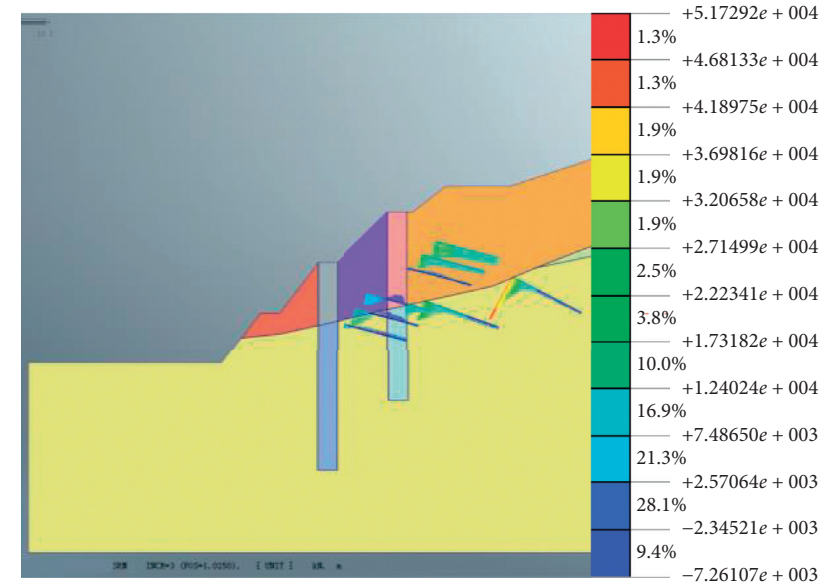

(b)

FIgURE 16: Cloud diagrams of prestressed anchor cable considering steady-state seepage: (a) axial force; (b) axial stress.

TABLE 5: Extreme value of each operating condition.

\begin{tabular}{|c|c|c|c|c|c|c|c|c|}
\hline \multirow{2}{*}{$\begin{array}{l}\text { Operated } \\
\text { condition }\end{array}$} & \multirow{2}{*}{$\begin{array}{c}\text { Pore water } \\
\text { pressure }\end{array}$} & \multirow[b]{2}{*}{$\begin{array}{l}\text { Axial force } \\
\qquad(\mathrm{kN})\end{array}$} & \multicolumn{2}{|c|}{ Antislide pile } & \multicolumn{3}{|c|}{ Anchor cable } & \multirow[b]{2}{*}{ Safety factor } \\
\hline & & & $\begin{array}{c}\text { Axial stress } \\
\left(\mathrm{kN} / \mathrm{m}^{2}\right)\end{array}$ & $\begin{array}{c}\text { Shear force } \\
(\mathrm{kN})\end{array}$ & $\begin{array}{c}\text { Bending } \\
\text { moment }(\mathrm{kN} \cdot \mathrm{m})\end{array}$ & $\begin{array}{l}\text { Axial force } \\
\quad(\mathrm{kN})\end{array}$ & $\begin{array}{l}\text { Axial stress } \\
\left(\mathrm{kN} / \mathrm{m}^{2}\right)\end{array}$ & \\
\hline \multirow{2}{*}{ First support } & No & $-4.25076 e 3$ & $-5.90383 e 2$ & $-1.87276 e 3$ & $-1.28113 e 4$ & $8.36198 e 2$ & $4.73191 e 4$ & 1.0219 \\
\hline & Yes & $-4.27074 e 3$ & $-5.93158 e 2$ & $-1.87355 e 3$ & $-1.26005 e 4$ & $9.29907 e 2$ & $5.26220 e 4$ & 1.0188 \\
\hline & No & $-5.96582 e 3$ & $-8.28586 e 2$ & $-1.44887 e 3$ & $-1.00180 e 4$ & $9.17205 e 2$ & $5.19032 e 4$ & 1.0754 \\
\hline support & Yes & $-6.13164 e 3$ & $-8.51617 e 2$ & $-1.40366 e 3$ & $-9.37553 e 3$ & $9.14130 e 2$ & $5.17292 e 4$ & 1.0250 \\
\hline
\end{tabular}

Figure 16 shows the stress analysis of the prestressed anchor cable for the secondary support when steady-state seepage is considered. Figure 16(a) shows that the maximum axial force of the prestressed anchor cable is $9.14130 e 2 \mathrm{kN}$. This maximum force occurs at the junction of the anchoring section and the free section of the prestressed anchor cable along the third-grade slope. The axial force of the upper two layers of prestressed anchor cables along the second- and third-grade slopes from the first support structure is still significantly greater than that of the first cable layer. Figure 16(b) shows that the maximum axial stress of the prestressed anchor cable is $5.17292 e 4 \mathrm{kN} / \mathrm{m}^{2}$, and the location and characteristics of the axial stress distribution are consistent with the axial force.

After considering the effects of steady-state seepage, the maximum axial force of the prestressed anchor cable is reduced by $0.33 \%$ and the maximum axial stress is reduced by $0.37 \%$ compared to when seepage effects are disregarded. There is no obvious change in the distribution location of maximum axial force or stress. Thus, steady-state seepage has little effect on the axial force and axial stress of the secondary prestressed anchor cable.

After the second support, the axial force of the prestressed anchor cable applied to the first support during steady-state seepage is $3.92908 e 2 \mathrm{kN}$. This value is only $42.25 \%$ of the extreme value of the axial force of the anchor cable after the initial support. It is proved that the additional anchor cable added in the secondary support has a significant effect on the first support anchor cable in sharing the pullout resistance. Table 5 shows the extreme force statistics of antislide piles and prestressed anchor cables before and after pore water pressure is applied.

\section{Discussion}

This study investigated the right side slope treatment project of a highway in Guizhou Province. Deep displacement monitoring data were used in conjunction with the $P$ value test method to validate the simulation parameters. The strength reduction method was used to perform finite element simulation on the two slope reinforcement treatments of the dual-structure slope, and the effect of applying pore water pressure on the mechanical characteristics of the slope-supporting structures (antislide piles and anchor cables) was examined. The key findings of this work are outlined below.

First, the deep displacement monitoring data and $P$ value testing were used to prove that the physical and mechanical parameters used in the initial simulation were reasonable. This represents a novel method to address the challenge of fuzzy parameter selection basis in numerical simulation. This method can be extended to other commercial or selfprogrammed software beyond the one used here. Accordingly, this method is expected to bridge the gap 
between on-site monitoring and numerical simulation. We also proposed a design process analysis method for supporting structures in conjunction with the self-verification approach, which requires further study. Significantly, these approaches were applied to a complex, binary-structure slope, which is a novel addition to previous work.

Second, based on the strength reduction method and finite element analysis, the effects of steady-state seepage on the stability of the dual-structure slope and its supporting structures were considered in depth. It was found that after the initial support structure was constructed, steady-state seepage had limited effect on the axial force, axial stress, shear force, and bending moment on the antislide pile. However, seepage did have a significant effect on the axial force and stress of the prestressed anchor cable. Notably, for three layers of prestressed anchor cable on the same slope, the upper two layers of anchor cable experienced five times the maximum force and stress of the lowest layer of anchor cable. This effect should be carefully considered in the design and construction process of anchor cable support structures, and the prestress value applied to the three layers of anchor cables should be adjusted appropriately.

After considering the seepage effects on the secondary support structure, it was determined that there were minimal effects on the maximum axial force and stress but more significant effects on the shear resistance and bending moment of the antislide piles. There were minimal seepage effects on the axial force and stress of the prestressed anchor cable of the secondary support structure; however, the discrepancy of force and stress between the upper and lower layers of cables remained. This should be carefully considered in the design of a secondary support structure and the prestress applied to the anchor cables.

In considering the differences between the primary support alone and the primary and secondary supports together, it was determined that the secondary support structure reduces the shear force and bending moment on the primary antislide pile. Furthermore, the maximum shear force and bending moment applied to the secondary support was approximately $60 \%$ of that applied to the primary structure alone. With regard to the prestressed anchor cables, there was a significant reduction in maximum axial force after addition of the secondary support. Thus, the secondary antislide pile provides significant additional resistance to sliding and the anchor cables of the secondary support provide additional resistance compared to the primary support anchor cables. Accordingly, the load is shared between the supports and the required flexural and shear resistance of the secondary antislide pile is not maximized. These features should be considered in the design and construction of supplemental support structures.

\section{Conclusions}

Previous analysis of the stress and deformation of supporting structures for the excavation of binary slopes has largely been centered on the simulation of the state of the supporting structure with set parameters. To date, there has been no clear method for validating parameters or a corresponding process analysis approach. In this study, we used deep displacement monitoring data and $P$ value testing to verify the parameters used for the simulation of a binary-structure slope considering different stages of support structure construction and steady-state seepage. Using the resulting simulations, we performed a systematic analysis of the differences in the stress and deformation of the support structures before and after steady-state seepage was applied by superposition. The results of this work have great significance for guiding robust future analysis of supporting structures for binary-structure slope during the rainy season.

\section{Data Availability}

The data used to support the findings of this study are included in the article.

\section{Conflicts of Interest}

The authors have no conflicts of interest to declare.

\section{Acknowledgments}

This study was supported by the Western Transportation Construction Science and Technology Project (2006-318000-07), the CCCC (China Communications Construction Co., Ltd) Technology Research and Development Project (2011-ZJKJ-01), the National Natural Science Foundation of China (51708043), and the Fundamental Research Funds for the Central Universities, CHD (300102219106 and 300102219209).

\section{References}

[1] Y. R. Zheng, Z. Y. Chen, G. X. Wang, and T. Q. Ling, Engineering Treatment of Slope \& Landslide, People's Communication Press, Beijing, China, 2nd edition, 2010.

[2] Editorial Board of Engineering Geology Manual, Handbook of Engineering Geology, China Construction Industry Press, Beijing, China, 4th edition, 2007.

[3] Z. Dai, Y. Shi, and H. Chai, "Physical simulation study on deformation and failure mechanism of gently inclined layered high slopes," Journal China Highway, vol. 17, no. 2, pp. 32-36, 2004.

[4] T. Nian and S. Yang, Theory of Engineering Practice of Landslide Treatment, China Railway Publishing House, Beijing, China, 1996.

[5] X. Chen, "Research on action mechanism and reinforcement effect of prestressed anchor pile based on FLAC3D," Rock Soil Mechanics, vol. 30, no. S2, pp. 499-501, 2009.

[6] A. J. Hyet, W. A. Bawden, and T. D. Reichert, "Stability of large excavations in laminated hard rock masses: the voussoir analogue revisited," International Journal of Rock Mechanics and Mining Sciences, vol. 29, no. 5, pp. 97-117, 1992.

[7] Y.-Y. Jiao, Z.-H. Wang, X.-Z. Wang, A. C. Adoko, and Z.-X. Yang, "Stability assessment of an ancient landslide crossed by two coal mine tunnels," Engineering Geology, vol. 159, pp. 36-44, 2013.

[8] D. W. Wilson, A. J. Abbo, S. W. Sloan, and A. V. Lyamin, "Undrained stability of a square tunnel where the shear 
strength increases linearly with depth," Computers and Geotechnics, vol. 49, pp. 314-325, 2013.

[9] X. Guo and M. Wang, "Efficacy analysis of anchors in tunnel supporting structure," Rock Soil Mechanics, vol. 28, no. 10, pp. 2234-2239, 2007.

[10] X. Zhu, Q. Yang, and M. Luan, "Research on rock anchorage effect and analytical constitutive model of bolt," Rock Soil Mechanics, vol. 28, no. 3, pp. 527-532, 2007.

[11] R. He, P. Zhang, and B. Liu, "Theoretical and numerical analysis of the bolt pull-out test," Rock Soil Mechanics, vol. 27, pp. 855-859, 2006.

[12] J. Jia, W. Zheng, and G. Chen, "Numerical analysis of prestressed anchor flexible retaining method," Chinese Journal of Rock Mechanics and Engineering, vol. 24, no. 21, pp. 39783982, 2005.

[13] L. Wei and C. Chen, "Three-dimensional numerical simulation method of bolt," Rock Soil Mechanics, vol. 21, pp. 315-320, 2007.

[14] H. Lin and P. Cao, "Numerical analysis of the influence of bolt length on slope stability," Chinese Journal of Geotechnical Engineering, vol. 31, no. 3, pp. 470-474, 2009.

[15] D. E. L. Ong, C. F. Leung, and Y. K. Chow, "Piles subject to excavation-induced soil movement in clay," in Proceedings of the 13th European Conference on Soil Mechanics and Geotechnical Engineering, vol. 2, pp. 777-782, Prague, Czech Republic, 2003.

[16] D. E. L. Ong, C. F. Leung, and Y. K. Chow, "Time-dependent pile behaviour due to excavation-induced soil movement in clay," in Proceedings of the 12th Pan-American Conference on Soil Mechanics and Geotechnical Engineering, vol. 2, pp. 2035-2040, Boston, MA, USA, 2003.

[17] D. E. L. Ong and C. S. Choo, "Sustainable bored pile construction in erratic phyllite," in Proceedings of the 2011 ASEAN-Australian Engineering Congress, pp. 50-65, Kuching, Malaysia, 2011.

[18] D. E. L. Ong, D. Q. Yang, and S. K. Phang, "Comparison of finite element modelling of a deep excavation using SAGECRISP and PLAXIS," in Proceedings of the 2006 International Conference on Deep Excavations, pp. 50-63, Singapore, 2006.

[19] D. E. L. Ong, C. F. Leung, Y. K. Chow, and T. G. Ng, "Severe damage of a pile group due to slope failure," Journal of Geotechnical and Geoenvironmental Engineering, American Society of Civil Engineers (ASCE), vol. 141, no. 5, Article ID 04015014, 2015.

[20] A. Mehdizadeh, M. Disfani, R. Evans, A. Arulrajah, and D. E. L. Ong, "Discussion of development of an internal camera-based volume determination system for triaxial testing," Geotechnical Testing Journal, vol. 39, no. 1, pp. 165-168, 2016.

[21] A. Mehdizadeh, M. Disfani, R. Evans, A. Arulrajah, and D. E. L. Ong, "Mechanical consequences of suffusion on undrained behaviour of a gap-graded cohesionless soil-an experimental approach," Geotechnical Testing Journal, vol. 40, no. 6, pp. 1026-1042, 2017.

[22] C. S. Choo and D. E. L. Ong, "Assessment of non-linear rock strength parameters for the estimation of pipe-jacking forces. Part 2. Numerical modeling," Engineering Geology, vol. 265, no. 2, pp. 105405-106172, 2020. 